\title{
THE TIME-AVERAGED PALEOMAGNETIC FIELD
}

\author{
David A. Schneider ${ }^{1}$ and Dennis V. Kent \\ Lamont-Doherty Geological Observatory and \\ Department of Geological Sciences \\ Columbia University, Palisades, New York
}

\begin{abstract}
We review indications of persistent deviations from the geocentric axial dipole model of the timeaveraged geomagnetic field and present a zonal harmonic model derived from 185 deep-sea sediment piston cores taken from low to middle latitudes (to approximately $\pm 45^{\circ}$ ). Analysis of the paleomagnetic inclination recorded in these cores for the Brunhes (normal polarity; 0-73 Ma) and Matuyama (reverse polarity; 0.73-2.47. $\mathrm{Ma}$ ) chrons, after plate motion correction, gives well-constrained estimates of the dominant long-term nondipole contributions (the axial quadrupole and axial octupole) and shows no significant deviation from axial symmetry. The amplitude of the axial quadrupole is found to vary with polarity $(2.6 \%$ of the geocentric axial dipole for normal;
\end{abstract}

4.6\% for reverse), while the axial octupole does not show appreciable change ( $-2.9 \%$ for normal; $-2.1 \%$ for reverse). These estimates of the quadrupole contribution agree well with prior determinations for the Plio-Pleistocene (0-5 $\mathrm{Ma}$ ); however, the octupole contribution we find is opposite in sign to previous estimates. We suggest that a negative octupole is representative of the actual timeaveraged paleomagnetic field, while prior positive octupole estimates probably reflect spurious inclination shallowing. The lack of polarity asymmetry in the octupole suggests that this nondipole component may be more closely linked to the main dipole field than is the quadrupole and so supports models of the geodynamo in which dipole and quadrupole families do not interact.

\section{THE GEOCENTRIC AXIAL DIPOLE MODEL}

Although Earth's magnetic field is largely dipolar, the direction of magnetic and geographic north are rarely the same. Indeed, deviations greater than $10^{\circ}$ are commonplace. Repeating measurements of the magnetic field over a period of years reveals that the direction of the field also varies with time. And so it becomes clear that the configuration of the magnetic field at a given moment in the remote geologic past cannot be predicted exactly. How then can paleomagnetic measurements be used to determine the ancient orientation of rocks with any precision?

The solution, of course, is to consider a statistical property of the field. Although Earth's instantaneous magnetic field is highly irregular, when averaged over perhaps several tens of thousands of years [McElhinny and Merrill, 1975], the mean field acquires a simple configuration, largely corresponding to a magnetic dipole aligned with the rotation axis and located at Earth's center. This assertion constitutes what, in the study of paleomagnetism, has been termed the geocentric axial dipole (GAD) hypothesis. Although there exists no rigorous theoretical

\footnotetext{
${ }^{1}$ Now at Centre des Faibles Radioactivités, Laboratoire Mixte CNRS-CEA, Gif-sur-Yvette, France.
}

basis for the GAD hypothesis in dynamo theory, the hypothesis remains intuitively appealing: because the higher-order features of the present geomagnetic field change most rapidly [Latham, 1988], time-averaging likely attenuates these most quickly, leaving a predominantly dipolar field. Earth's overall axial symmetry gives no preferred direction for maintaining any offset or tilt of the average dipole field. Thus the GAD time-averaged configuration of the magnetic field of the past can be assumed and used as a stable reference (the so-called paleomagnetic field) for the many tectonic applications of paleomagnetism.

The critical importance of the GAD hypothesis has led workers to test its validity experimentally by examining paleomagnetic directions from relatively young rocks (those which have presumably moved little since becoming magnetized). Evidence garnered for many early paleomagnetic studies [e.g., Hospers, 1954; Cox and Doell, 1960; Irving, 1964; Opdyke and Henry, 1969] and archeomagnetic investigation [Champion, 1980] largely supported the GAD hypothesis, at least for recent intervals, showing that time-averaged paleomagnetic inclinations could be predicted from the geocentric axial dipole formula: 
Indeed, Evans [1976] found that a dipolar field could best explain the distribution of paleomagnetic inclinations recorded in continental rocks from all continents over the Phanerozoic. Although Evans's analysis does not confirm the axial nature of the field, comparisons of the GAD model with various paleoclimate indicators [e.g., Irving, 1964], as well as the success of voluminous paleomagnetic work in documenting tectonic motion, also attest to the general applicability of the GAD hypothesis even to the remote geologic past.

\section{DEVIATIONS FROM THE GEOCENTRIC AXIAL DIPOLE}

\section{Offset Dipole Representation}

Despite the general success of the GAD model in describing the paleomagnetic field, second-order discrepancies have been observed. The significance of these was first expounded by R. L. Wilson [Wilson and AdeHall, 1970], who noted a tendency for paleomagnetic pole positions (projections of the equivalent geocentric dipole) to lie on the far side of the geographic pole when viewed from the sampling site. He interpreted this far-sidedness by modifying the GAD model to include a small northward offset of the axial dipole along the rotation axis. Wilson's [1970, 1971, 1972] analyses of dipole offset not only described the mean field configuration in increasing detail, but also offered a simple physical model.

In one study [Wilson, 1970], Wilson included paleomagnetic data from 66 deep-sea sediment cores [Opdyke and Henry, 1969] and found that the value of offset differed for normal polarity compared with reverse polarity. He ascribed this difference to a genuine polarity dependence, which he found also in published upper Tertiary and Quaternary paleomagnetic data from the USSR [Wilson, 1972]. Later, however, some of these effects were ascribed to variations of the field with time [Wilson and McElhinny, 1974].

Wilson [1971, 1972] also noted a tendency toward easterly declinations, which he labeled a right-handed effect. Because such a right-handed effect implies unacceptably large currents crossing Earth's surface, this observation has remained suspect. The right-handed bias originally noted by Wilson does not appear to be a consistent global effect [Andrews, 1985] and probably resulted from the presence of some tectonic rotation combined with the uneven distribution of data sites available for these early studies.

\section{Spherical Harmonic Representation}

Since Wilson's original work, other attempts to elaborate on the GAD model [Creer et al., 1973; Georgi, 1974; Merrill and McElhinny, 1977; Coupland and Van der Voo, 1980; Livermore et al., 1983, 1984] have, by analogy with studies of the present geomagnetic field, used spherical harmonic analysis. The object of such analysis is to estimate values of the various Gauss coefficients, $g_{n}^{m}$ and $h_{n}^{m}$, which specify the potential $V$ of the internal magnetic field according to the relation [Merrill and McElhinny, 1977]

$$
\begin{aligned}
V=a \sum_{n=1}^{\infty}(a / r)^{n+1} \sum_{m=0}^{n}\left(g_{n}^{m} \cos m \phi\right. & \\
& \left.\quad+h_{n}^{m} \sin m \phi\right) P_{n}^{m}(\cos \theta)
\end{aligned}
$$

where $\theta, \phi$, and $r$ are the usual spherical coordinates of colatitude, longitude, and radial distance, $a$ is the mean radius of Earth, and $P_{n}^{m}$ are the Schmidt-normalized Legendre polynomials.

Although the practice of fitting Earth's magnetic field with spherical harmonic functions is well established for the present-day geomagnetic field [Chapman and Bartels, 1940], the application to paleomagnetic data is more difficult: paleomagnetic measurements do not normally give field intensity, nor are they likely to be from sites as numerous or as well distributed as is the case in modeling the present geomagnetic field. Although it is not obvious that spherical harmonic analysis of paleomagnetic data can determine the time-averaged field uniquely, Kono [1976] showed that two fields which satisfy directional data can differ only by a multiplicative constant. This then allows the usual procedure of estimating the magnitude of the various spherical harmonic coefficients in terms of their ratios with the $g_{1}^{0}$ (the geocentric axial dipole) component.

The uniqueness of a given spherical harmonic fit, however, will depend on the adequacy of the distribution of data sites. Were the field everywhere known, each spherical harmonic component could be determined separately by the appropriate integration, and this estimate would be independent of the other components. Difficulties arise in practice because the spherical harmonic functions are not strictly orthogonal over data sets that are limited in distribution and quality. Consequently, component magnitudes must be determined simultaneously by minimizing errors, and the results will depend on the number of components included in such minimizations.

Representations of the field in terms of dipole eccentricity (axial offset, equatorial offset, and titt) can be related to equivalent spherical harmonic expansions. Eccentric dipole models can, according to Fraser-Smith [1987], be adequately described by including spherical harmonic terms to degree and order 2. Although other formulations of eccentric dipole models include third- and higher-order terms [e.g., James and Welch, 1967], for practical purposes these terms can be considered negligibly small. We summarize the important associations between dipole eccentricity and specific spherical harmonic components in Table 1. For example, a dipole tilt of $5^{\circ}$ toward $45^{\circ}$ longitude could be expressed, using spherical harmonics, by specifying equatorial dipole terms $\left(g_{1}^{1}\right.$ and $\left.h_{1}^{1}\right)$ that are $6 \%$ of the axial dipole term $\left(g_{1}^{0}\right)$. Similarly, an axial offset of, for instance, $150 \mathrm{~km}$ northward, is equivalent to adding $5 \%$ axial quadrupole $\left(g_{2}^{0}\right)$ to the axial dipole $\left(g_{1}^{0}\right)$. 
TABLE 1. Eccentric Dlpole Parameters and Related Gauss Coefficlents

\begin{tabular}{lc}
\hline \multicolumn{1}{c}{ Eccentric Dipole Parameter } & $\begin{array}{c}\text { Dominant } \\
\text { Gauss Coefficients }\end{array}$ \\
\hline$\Delta Z$ (axial offset) & $g_{2}^{0}$ \\
$\Delta X$ (equatorial offset: $0^{\circ}-180^{\circ}$ longitude) & $g_{2}^{1}$ \\
$\Delta Y$ (equatorial offset: $90^{\circ}-270^{\circ}$ longitude) & $h_{2}^{1}$ \\
$\theta, \Phi$ (dipole tilt) & $g_{1}^{1}, h_{1}^{1}$
\end{tabular}

$\theta, \Phi$ are the colatitude and longitude of the tilted dipole axis. Note that combinations of offsets and tilt would require the additional sectorial terms to degree and order 2 [Fraser-Smith, 1987].

In an ambitious early spherical harmonic study, Creer et al. [1973] analyzed the data originally considered by Wilson, to determine dipole eccentricity (that is, to fit each spherical harmonic coefficient up to degree and order 2). They also analyzed data of Quaternary to Recent age then available in published pole listings as well as the deep-sea core results from Opdyke and Henry [1969]. These authors found that the best fitting eccentric dipole for the Quaternary had only $1^{\circ}$ tilt but was offset $145 \mathrm{~km}$ north along the rotation axis and also $147 \mathrm{~km}$ away from the axis toward the Pacific. They noted, however, that significant differences emerged when different data sets were analyzed, suggesting that the quality and distribution of data then at hand were inadequate. Georgi [1974] continued this work by combining the terrestrial and deep-sea sediment results used by Creer et al. [1973] to fit coefficients as high as degree 3; however, he determined that only second-degree terms were significant, thus supporting the previous results of Creer et al. [1973].
Merrill and McElhinny [1977] later analyzed paleomagnetic results compiled from published pole listings as well as data procured directly from the original researchers. This allowed them to analyze separately normal and reverse polarity data which could not be distinguished from the published listings. After examining declination as a function of longitude, these authors concluded that nonzonal effects were probably small and so fit the zonal quadrupole $\left(g_{2}^{0}\right)$ and octupole $\left(g_{3}^{9}\right)$ terms in their analysis of the field. In a similar fashion, Coupland and Van der Voo [1980], using published pole listings, found little evidence for nonzonal components in the recent field, and they too estimated the zonal quadrupole and octupole. In contrast to these zonal harmonic analyses, Livermore et al. [1983] modeled the 0-5 Ma paleomagnetic field by fitting all terms up to degree 3 . They found almost all nonzonal terms to be small; however, the $h_{2}^{1}$ so determined appeared to be comparable in magnitude to the clearly significant zonal quadrupole and octupole terms.

\section{EXAMINATION OF DEEP-SEA SEDIMENTS}

In this paper we present a new analysis of the global time-averaged field for 0-2.5 Ma and compare our results with these prior studies. Our efforts differ from previous work principally in that we use paleomagnetic data from deep-sea sediments exclusively (Figure 1). Such sediments are known to retain a good record of Earth's ancient magnetic field [Opdyke, 1972; Harrison, 1974]; however, being sampled by piston coring, these sediments do not give paleomagnetic declination (the cores not being oriented in azimuth). Nevertheless, piston cores do provide a number of advantages compared to the fully

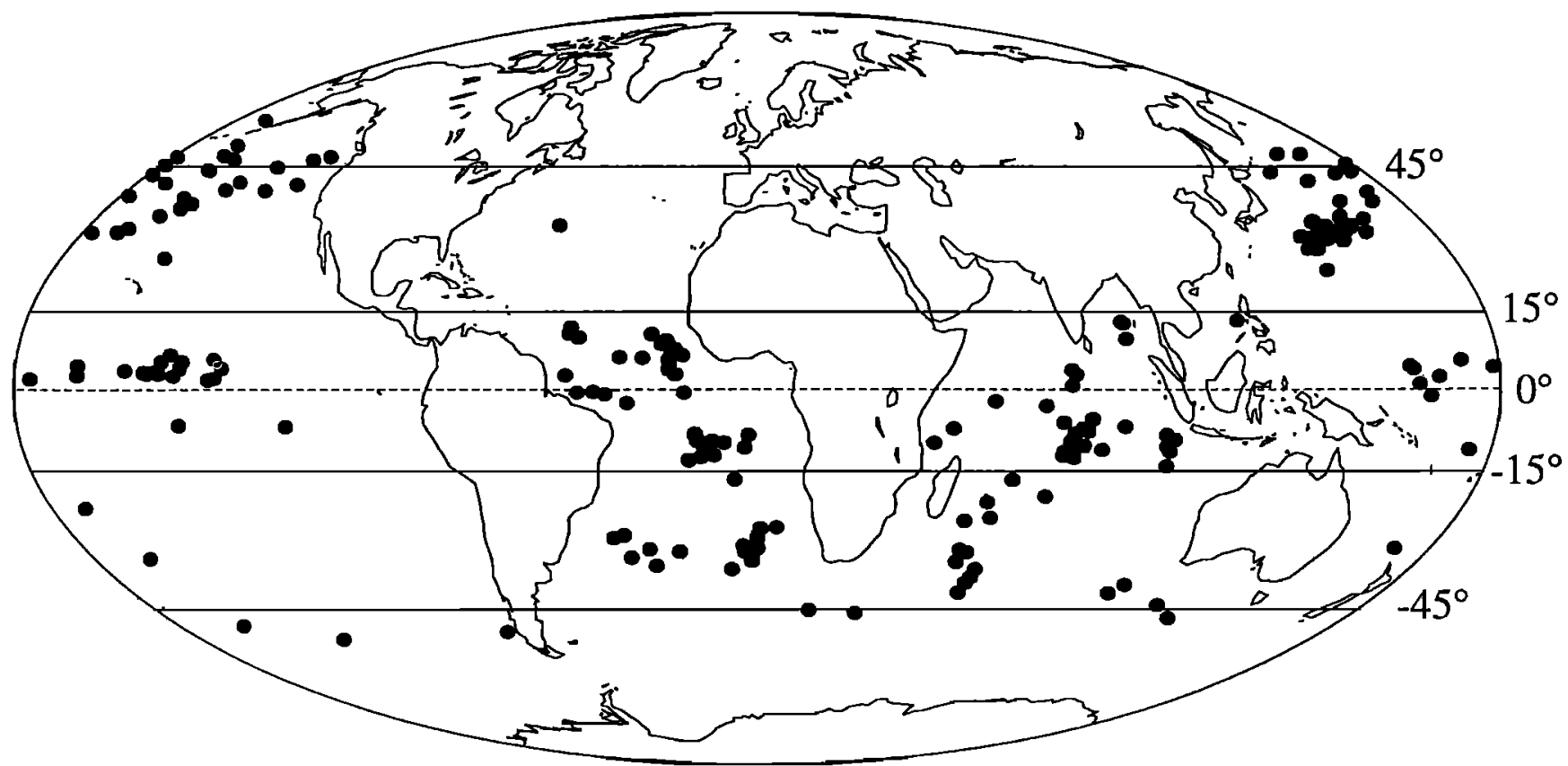

Figure 1. Site locations of the 186 piston cores used in this study. Equatorial cores $\left( \pm 15^{\circ}\right.$ latitude) from Schneider and Kent [1988b]. 
oriented continental data previously studied. First, and most obviously, the use of deep-sea sediments allows for a better geographic distribution of sampling sites than with land-based data, particularly in the Pacific and southern hemispheres. Also, the slow accumulation of pelagic sediment on the seafloor (typical rates are about $1 \mathrm{~cm}$ per 1000 years), combined with the ubiquitous bioturbation of these sediments (typical burrowing depths are about 10 $\mathrm{cm}$ ), suggests that significant averaging of the magnetic field is accomplished in situ, making deep-sea sediments particularly appropriate for a study of the time-averaged field. Furthermore, pelagic sediment cores can be readily dated by using the contained record of biostratigraphic events and magnetic reversals. This precision in age control permits plate tectonic corrections to be readily made and also allows time and polarity dependent effects to be easily distinguished. Finally, as we shall argue below, we believe that shallowly buried deep-sea sediments in general may be more reliable recorders of field inclination than are terrestrial sediments or lava flows.

Several of the above-mentioned studies used some deep-sea core data to supplement the largely land-based data sets; however, the core data available to these workers were limited, and their descriptions of the paleomagnetic field depended largely on results from terrestrial sediments and lavas. For our studies of the time-averaged field we sought to augment the body of deep-sea core data and mount an examination with a homogeneous data set that was independent of any land-based results. We first concentrated our efforts on generating new measurements and on reanalyzing published core data from equatorial latitudes [Schneider and Kent, 1988a, b] where we expected the dominant zonal quadrupole to have the greatest effect and various spurious effects to be at a minimum.

As with many of the previous studies, we found it useful to cast deviations from GAD directions as inclination anomalies [Cox, 1975]. The inclination anomaly is defined for each site latitude as the difference between the observed inclination and the geocentric axial dipole inclination:

$$
\Delta=I \text { (observed) }-\tan ^{-1}[2 \tan \text { (latitude) }]
$$

As has been customary, the sign of reverse polarity observed and dipole inclinations are inverted to give normal polarity equivalents. This inversion (which we do throughout) allows normal and reverse polarity inclination anomalies to be readily compared or combined.

Using this device, we could examine deviations from the GAD model without explicitly fitting harmonic coefficients, although at the equatorial latitudes studied, only the even-degree zonal harmonics (presumably the zonal quadrupole) were expected to contribute. We had excellent knowledge of both age and polarity in these cores and so could test whether the prior indications of polarity dependence could not be more simply explained by changes of the mean field with time.
Our equatorial results [Schneider and Kent, 1988b] indicated a strong polarity asymmetry: inclination anomalies were of consistently larger absolute magnitude for reverse polarity compared to normal polarity (Figure 2). This polarity asymmetry was observed for the four Plio-Pleistocene polarity chrons covering the past 5 m.y.; it was also seen within the Matuyama chron in comparing the Olduvai normal polarity subchron with reverse polarity intervals directly before and afterward. These equatorial core data did not, however, show any significant deviation from axial symmetry, nor did they show any temporal drift of the field over the past $5 \mathrm{~m}$.y. unassociated with polarity changes.

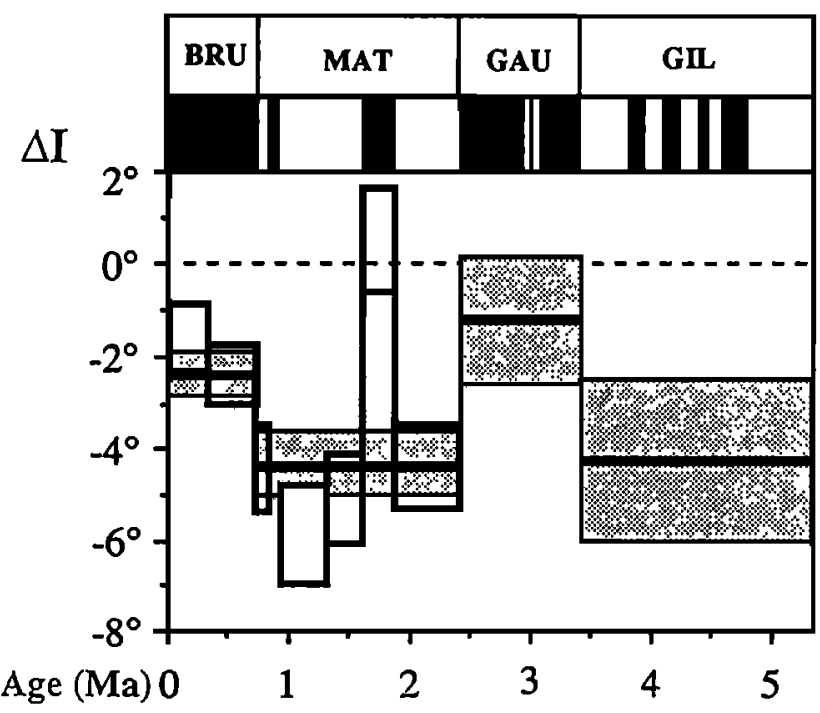

Figure 2. Average inclination anomaly (observed inclination minus dipole inclination) determined at equatorial latitudes. Note that reverse polarity inclination anomalies are inverted in sign to give normal polarity equivalents (see text). Solid horizontal lines/shaded areas show mean and $1 \sigma$ errors for averaging windows corresponding to the four geomagnetic polarity chrons of the Plio-Pleistocene (data representing subchrons removed). Bold boxed areas show $1 \sigma$ error limits for narrower averaging windows within the Brunhes and Matuyama chrons, including an average for the Olduvai (1.66-1.88 Ma) normal polarity subchron. (After Schneider and Kent [1988b].)

\section{A Global Sediment Core Data Set}

To resolve zonal terms of higher degree than the quadrupole, we have expanded our previous equatorial data set to include cores from northem and southern mid-latitudes (to approximately $\pm 45^{\circ}$ ) and consider paleomagnetic data from a total of 186 cores of Pliocene to Pleistocene age (Figure 1). As with the equatorial portion of the data, many of the cores were studied previously for various stratigraphic or geomagnetic studies [Hays et al., 1969; Opdyke and Glass, 1969; Opdyke and Henry, 1969; Opdyke and Foster, 1970; Shackleton and Opdyke, 1973, 1977; Burckle and Opdyke, 1977; Kent and Opdyke, 1977; Ninkovich et al., 1982; Clement and Kent, 1984; Johnson 
et al., 1989]. All of the northem mid-latitude cores we consider were examined during previous stratigraphic studies; however, many southern hemisphere core results are presented here for the first time. The paleomagnetic investigations undertaken for the earlier stratigraphic studies were often limited in the demagnetization level that could be applied. Nevertheless, even the relatively low demagnetication treatment appears to remove the spurious secondary components effectively in most cases: the scatter in directions is often no larger than with the higher demagnetication fields we used in generating new data. Furthermore, we specifically compared earlier core results against recent measurements in one region and found a good correspondence, at least in an average sense [Schneider and Kent, 1988a]. Thus we have freely combined original data from these previous studies with our new data.

To create the global data set, we examined paleomagnetic data from a total of 413 cores. Many of these data, however, proved to be highly scattered and clearly did not reflect a consistently recorded ancient magnetization, so that in many cases even the basic magnetostratigraphy was not interpretable. About half of the cores originally considered did, however, suggest a stable record of the ancient field, and we used these in our analysis (Table A1). The 186 cores selected were those that showed high internal consistency (the standard deviations of inclinations within each core were restricted, in general, to $15^{\circ}$ or less) and displayed a pattern of magnetic reversals that can be readily interpreted using available biostratigraphic control. In some instances we allowed somewhat more scatter in direction or uncertainty in age than was typical of most of the data, varying our selection criteria somewhat with geographic region. This flexibility allowed us to construct a data set which was largely balanced in northern and southern latitudes, which was relatively uniform in site longitude, and which was well representative of both normal and reverse polarities.

Our measurement and analytical procedures are similar to those described previously [Schneider and Kent, 1988a]. As with our previous studies using these cores, we separated the inclination data into groups corresponding to Plio-Pleistocene geomagnetic polarity chrons. In this analysis, two groups are considered: Brunhes $(0-0.73 \mathrm{Ma})$ and Matuyama (0.73-2.47 Ma). We calculate an average Brunhes inclination as well as an average Matuyama inclination from each core if that chron was represented by five or more samples, as one might do with a typical paleomagnetic site. We do not include any data corresponding to the various subchrons of the Matuyama so that each group is composed of uniformly normal (Brunhes) or uniformly reverse (Matuyama) polarity data. We can then take the results from these two groups to be representative of the normal (from the Brunhes data) and reverse (from the Matuyama data) polarity configurations of the time-averaged field which, on the basis of our equatorial core study, we expect to be distinct.
Because these cores were not oriented in azimuth, we must treat inclination-only data. To average these inclinations, we employ a maximum likelihood technique to remove the bias that would be associated with a simple arithmetic average [McFadden and Reid, 1982]. Note that in performing this correction we take care to use McFadden and Reid's equation (40) with the unhatted value of $\theta$ and not the hatted value as was incorrectly used in their numerical example (P. L. McFadden, personal communication, 1986), so the maximum likelihood estimates of inclination are always steeper than the simple arithmetic average. Typical bias corrections are about $1^{\circ}$. We also calculate the position of each coring site at the time of deposition by correcting the present-day coordinates for known plate motion. We determine this plate motion correction using the mean age assigned to each core/chron average with the absolute motion model AM1-2 of Minster and Jordan [1978]. The resultant inclination averages for the Brunhes and Matuyama data sets are given in Tables A2 and A3.

One should recognize that the results from a given core might well deviate from the actual inclination of the main time-averaged field at that site, for instance, because the core may not have penetrated vertically or because of local (crustal) magnetic anomalies. Any such errors, however, should vary randomly from core to core [Schneider and $K e n t, 1988 a$ ], so we give each core average equal weight in the following analysis, regardless of the number of samples or the scatter in the individual within-core measurements.

\section{Spherical Harmonic Analysis of Inclinations}

To first order, the mean inclinations determined for the Brunhes and Matuyama follow the variation with latitude expected from a geocentric axial dipole field (Figure 3). (Note that core RC14-120 provided internally consistent inclination values but falls far from the overall trend, and thus we exclude it from the analysis.) Although the fundamental observation is that these data follow a dipole trend, in detail the core inclinations do show slight but systematic departures from the GAD prediction. To fit the observations with a more complex field model, we must first, of course, decide which spherical harmonic coefficients to include as well as the appropriate quantity to minimize. We chose to fit only axially symmetric components. This decision is based on the results of the most recent spherical harmonic analyses [Merrill and McElhinny, 1977; Coupland and Van der Voo, 1980; Livermore et al., 1983], which indicate a predominantly zonal time-averaged field, as well as the intuitively simple notion that the westward drift of secular variation likely acts to average out nonzonal components [Cox, 1975].

In considering how many of the zonal terms to include we must take into account the limitations imposed by the distribution of data sites, especially the lack of suitable cores available from high latitudes. One reason for this is clear: there is relatively little ice-free ocean at the higher 
latitudes from which to take piston cores. In addition, the piston core data that are available often cannot be used because the maximum likelihood averaging procedure fails for inclinations too close to vertical (as scatter increases, the probability that some directions actually pass through vertical to shallower inclination angles of opposite declination also increases). Thus the higher latitudes simply cannot be well represented in this core study.

To examine the effect of the various zonal harmonics with latitude, it is useful to consider the inclination anomaly associated with each term (Figure 4). Note that $\Delta I$ is largely symmetric about the equator for the even harmonic terms (e.g., $g_{2}^{0}$ or $8_{4}^{9}$ and antisymmetric for the odd harmonics (e.g., g). (In detail, however, these symmetries in $\Delta I$ are not exact, although the slight discrepancy is not obvious unless the $\Delta$ values are large.) Because the effect of $g_{2}^{0}$ and $g_{4}^{0}$ is quite similar over the latitude range studied, we can anticipate that these two components will be difficult to distinguish with our limited high-latitude data.

In fitting our data to a zonal field model we minimize the sum of the squared differences between the observed and the predicted inclinations at each of the core sites. Thus the quantity minimized is

$$
\text { SSE } \left.=\sum[I \text { (observed })-I(\text { model })\right]^{2}
$$

where SSE is the sum of squared errors. We calculate the zonal harmonic model inclination using the relation [Livermore et al., 1983; D. Epp, personal communication, 1985],

$\tan [I($ model $)]$

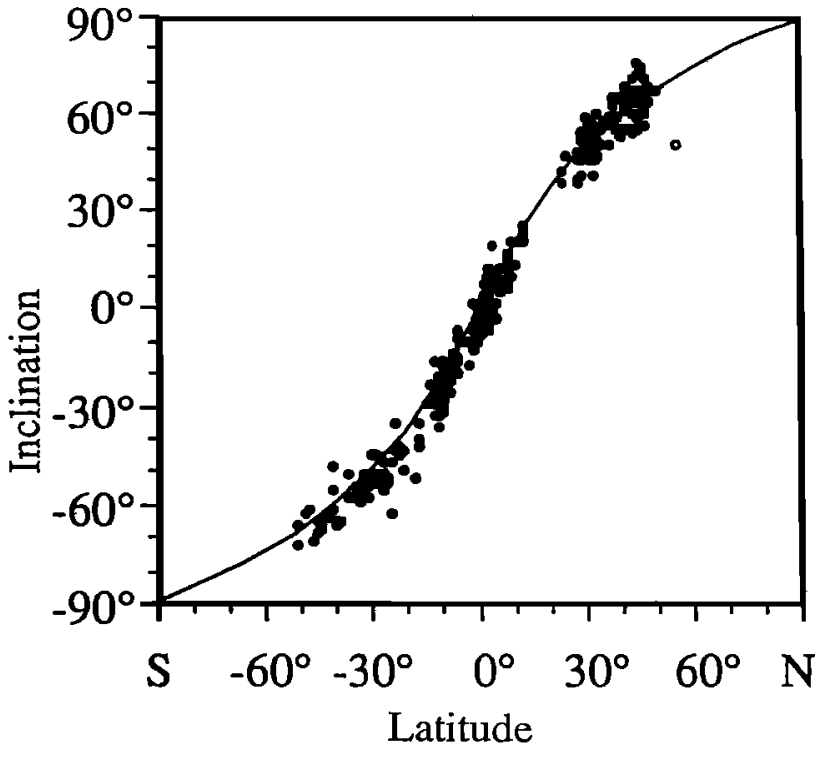

Figure 3. Average inclination for both Brumhes and Matuyama chrons from the $\mathbf{1 8 6}$ cores studied as a function of core latitude. Averages are computed using maximum likelihood technique as described in text. Core latitudes are restored using an absolute plate motion model. Solid curve indicates prediction of geocentric axial dipole model. Although the data fundamentally follow the geocentric axial dipole trend, consistent deviations are seen at equatorial and southern latitudes. Note that the single open point indicates an outlier (core RC14-120) not included in the final analysis of 185 cores. $=\frac{2 \cos \theta+G 2\left[(9 / 2) \cos ^{2} \theta-(3 / 2)\right]+G 3\left(10 \cos ^{3} \theta-6 \cos \theta\right)+G 4\left[(175 / 8) \cos ^{4} \theta-(75 / 4) \cos ^{2} \theta+(15 / 8)\right]}{\sin \theta+G 2(3 \sin \theta \cos \theta)+G 3\left[(15 / 2) \sin \theta \cos ^{2} \theta-(3 / 2) \sin \theta\right]+G 4\left[(35 / 2) \cos ^{3} \theta \sin \theta-(15 / 2) \cos \theta \sin \theta\right]}$

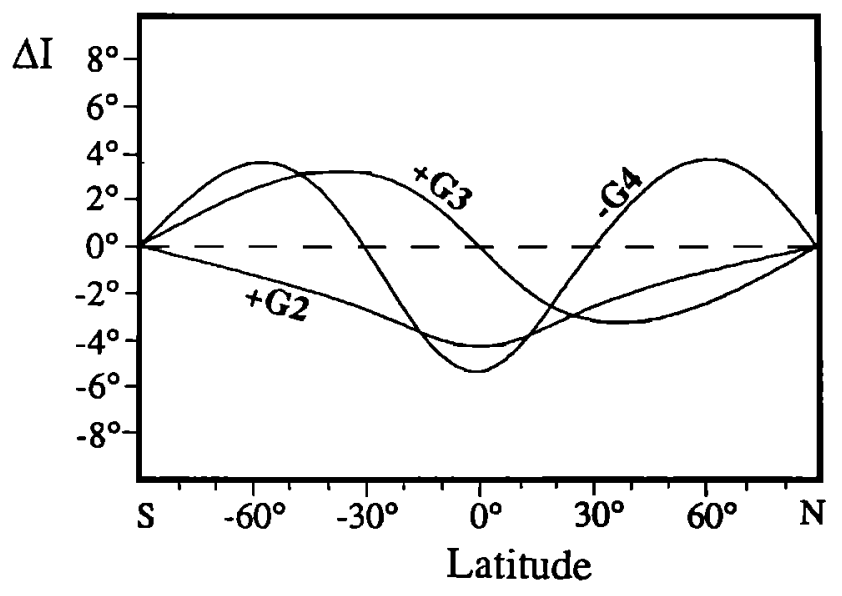

Figure 4. Variation in predicted inclination anomaly $(\Delta l)$ as a function of latitude for low-degree zonal harmonic models containing illustrative values of the axial quadrupole $\left(g_{2}^{0}\right)$, axial octupole $\left(g_{3}^{0}\right)$, and axial hexadecapole $\left(g_{4}^{0}\right)$.G2: $g_{2}^{0} / g_{1}^{0}=0.05 . G 3: g_{3}^{0} /$ $g_{1}^{0}=0.05$. G4: $g_{4}^{0} / g_{1}^{0}=-0.05$. Note that the predicted anomalies for the $G 2$ and $G 4$ models show largely even symmetry, while that for the $G 3$ model shows largely odd symmetry about the equator. where $\theta$ is the (paleo)colatitude and upper case denotes ratios of the zonal Gauss coefficients to the GAD: $G 2=g_{2}^{0} /$ $g_{1}^{0} ; G 3=g_{3}^{0} / g_{1}^{0} ; G 4=g_{4}^{0} / g_{1}^{0}$. (Note that equation (5) may have been incorrectly formulated in some previous nondipole studies. In reporting their previous work and the unpublished work of Lee and McElhinny, Merrill and McElhinny [1983] misstate the $G 3$ term in the denominator of their equation (6.7) $\left(3 \sin \theta\right.$ should be $\left.\frac{3}{2} \sin \theta\right)$ and appear, on the basis of their Figure 6.7, to use incorrect coefficients for the $G 4$ terms (D. Epp, personal communication, 1985). Coupland and Van der Voo [1980] similarly misrepresent the $G 3$ term and, judging from their Figure 5, appear to use this incorrect equation in their calculations.)

We examined our ability to model the first three zonal terms by mapping an error ellipsoid in the G2-G3-G4 parameter space. Contours of root-mean-square (rms) error are shown on the G2-G3, G2-G4, and G3-G4 planes in Figure 5. These surfaces show a number of interesting features. Because the principal axes of the error ellipses lie parallel to the coordinate axes in two of the sections (G2-G3 and G3-G4), the estimates of these harmonics can 


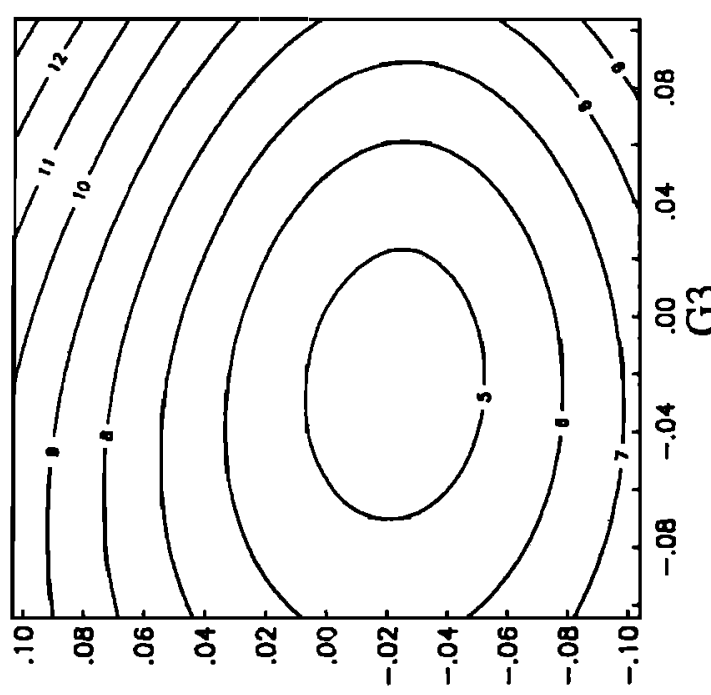
tD
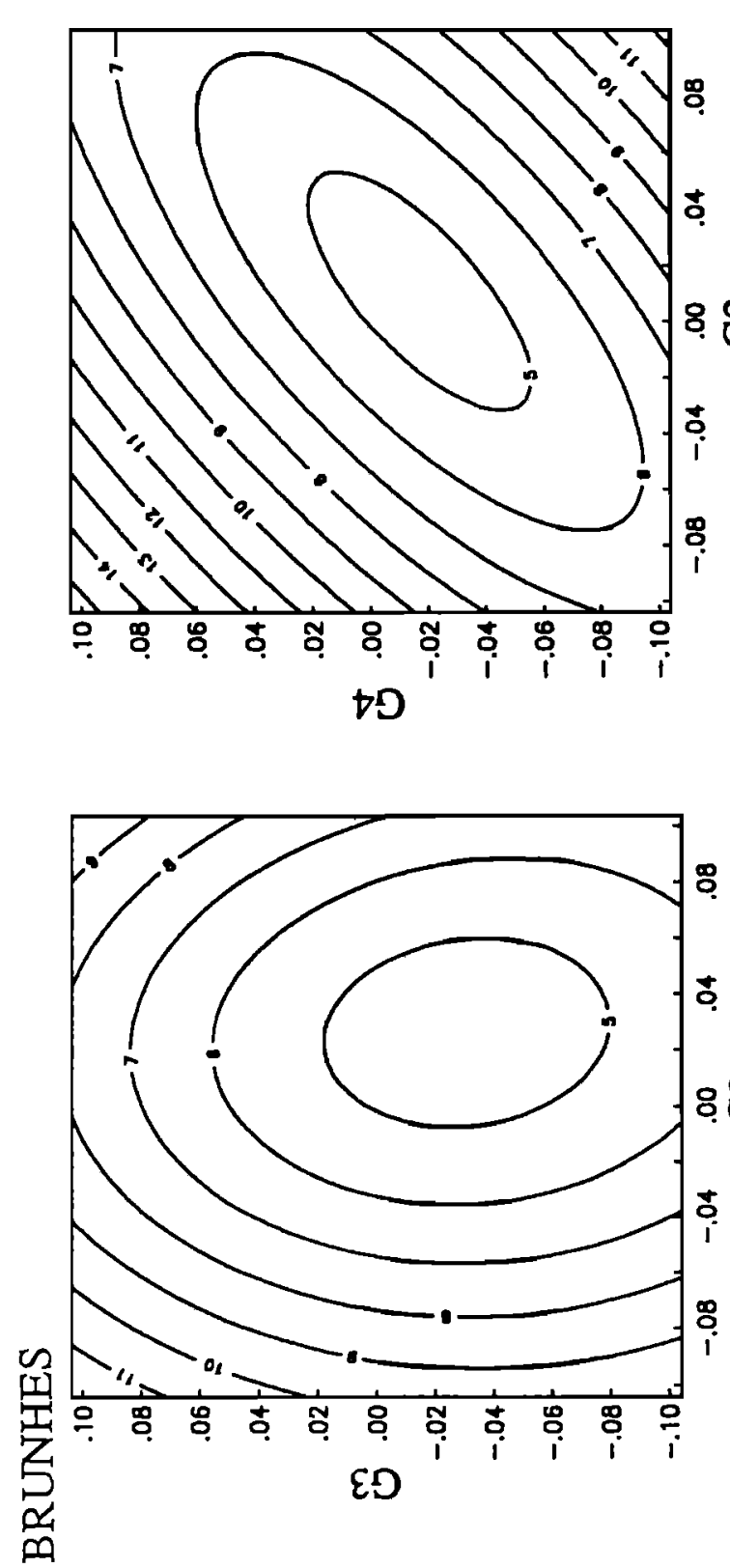
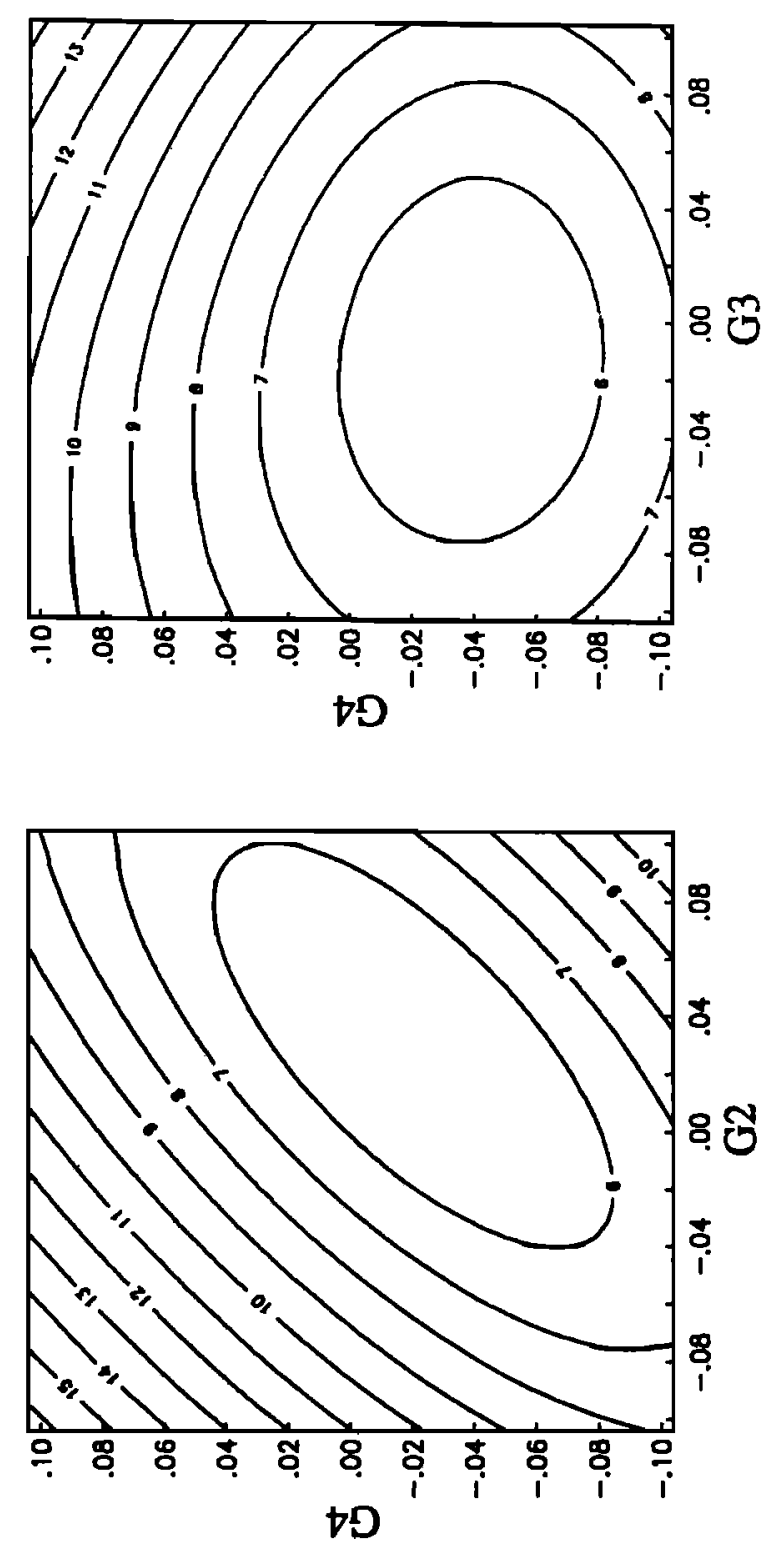

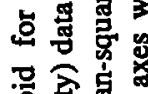

骂艺

总哥早

尌

量

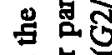

总 氙

s.

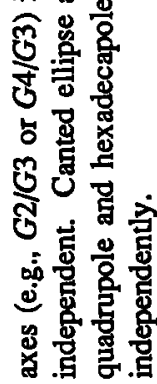

震

ठี่ 实高

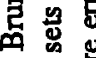

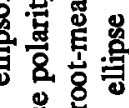

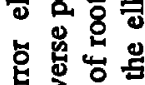
s.

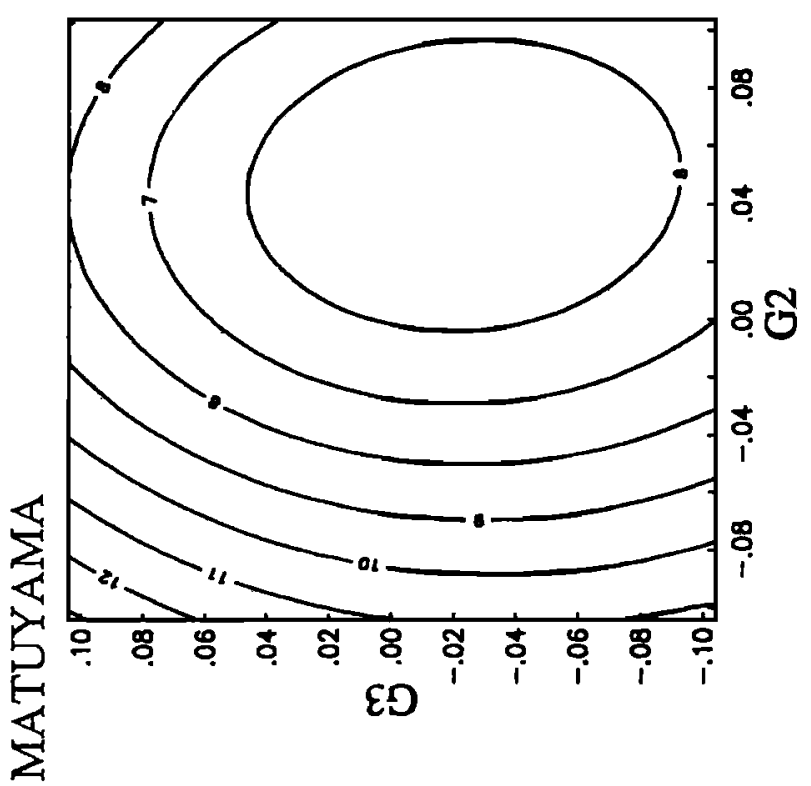


be determined independently. The canted axes in the G2-G4 section, however, indicate that these two even harmonics caninot be easily distinguished: the best fitting value of $G 2$ will depend on the choice. of $G 4$, and vice versa. Presumably, a similar picture would emerge if we had mapped a G3-G5 section of the error hyperellipsoid.

Although we can, of course, find the model that minimizes the error for any number of components, we prefer to fit only the lowest-degree even and odd harmonic terms, $G 2$ and $G 3$, in this analysis. Although we may well be casting (i.e., aliasing) higher-degree effects in these two terms, this approach should nevertheless maintain a good separation between even and odd symmetry components. In addition, the demonstrated independence of these two terms allows us to calculate formal error limits associated with each. To estimate these errors, we used the relation [Menke, 1984]

$$
[\operatorname{cov} \mathbf{m}]=\sigma_{d}^{2}\left[(1 / 2) \partial^{2}(\operatorname{SSE}) / \partial m^{2}\right]_{m=m_{c a}}^{-1}
$$

for the variance of the least squares solution. Here [cov m] is simply a diagonal matrix describing the variances in the G2 and G3 estimates, and SSE is the sum of squared errors computed for the minimization (equation (4)). The variance of the data, $\sigma_{d}$, is equated to the best fitting $\mathrm{ms}$ value. We computed the required derivatives of SSE from closely spaced values about the best fit.

We determined the best estimates for $G 2$ and $G 3$ and their associated errors for the Brunhes (normal polarity) and Matuyama (reverse polarity) separately (Table 2). Although admittedly there is scatter in the data about the best fitting model (Figure 6), one can readily see from

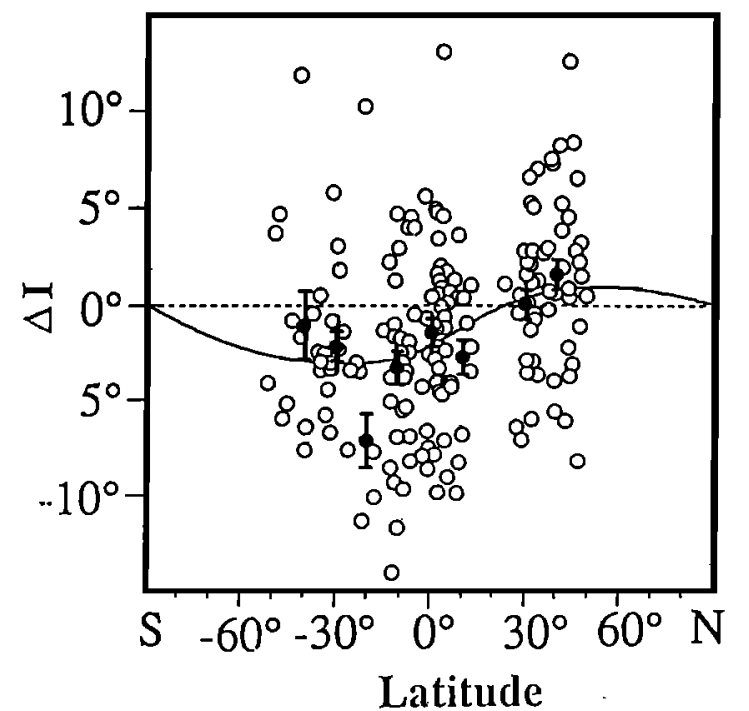

TABLE 2. Best Fitting Quadrupole (G2) and Octupole (G3) Values and Their $2 \sigma$ Error Limits

\begin{tabular}{lccc}
\hline \multicolumn{1}{c}{ Chron (Polarity) } & $N$ & $G 2$ & $G 3$ \\
\hline Brunhes (normal) & 175 & $0.026 \pm 0.010$ & $-0.029 \pm 0.015$ \\
Matuyama (reverse) & 125 & $0.046 \pm 0.014$ & $-0.021 \pm 0.020$
\end{tabular}

$N$, number of cores.

Table 2 that the size of these terms is always significantly larger than the estimated errors (quoted at the $2 \sigma$ level throughout). Moreover, we find that $G 2$ is nearly twice as large for the reverse polarity Matuyama $(0.046 \pm 0.014)$ as for the normal polarity Brunhes $(0.026 \pm 0.010)$. Our anạly'sis shows no significant difference, however, in the G3 estimates for the two opposite polarity intervals $(-0.029 \pm 0.015$ for normal compared with $-0.021 \pm 0.020$ for reverse).

\section{Examination of Axial Symmetry}

Although we have expressly overlooked deviations from axial symmetry in our zonal harmonic modeling of the paleomagnetic field, some examination of this possibility is warranted. Despite the several indications of axial symmetry already mentioned, three important reasons remain to suggest that the paleomagnetic field might contain detectable large-scale axial asymmetry. The first reason stems from the findings of recent studies of true polar wander (motion of the paleomagnetic axis with respect to the hotspot reference frame) which would suggest several degrees of polar motion during the Plio-Pleistocene [Morgan, 1981; Andrews, 1985; Courtillot and Besse, 1987]. We would expect such true polar

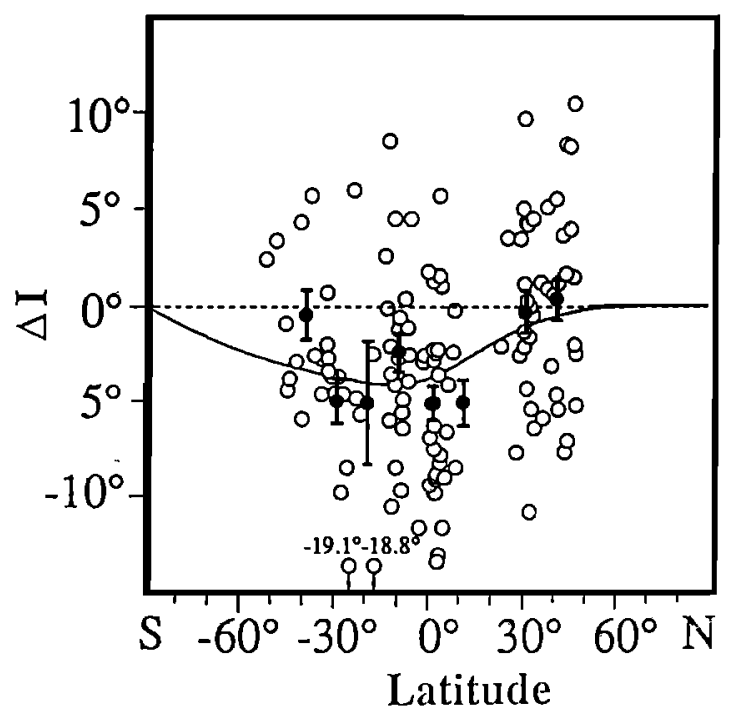

Figure 6. Inclination anomalies derived from (left) Brunhes nomal polarity data given in Table A2 and (right) Matuyama reverse polarity data given in Table A3. Open points are individual core inclination anomalies; solid points are averages of $10^{\circ}$ latitude bins centered on the equator (one standard error bars shown); solid curves indicate prediction of the best fitting zonal quadrupole/octupole model as given in Table 2. 
wander to appear as a consistent dipole tilt (or, equivalently, as the presence of nonzero equatorial dipole terms). The second motivation to look for large-scale asymmetry comes from studies of historical magnetic field observations [Bloxham and Gubbins, 1985] which showed significantly different behavior in the Atlantic and Pacific hemispheres, particularly because Gubbins [1988] also found that this east-west hemispheric asymmetry in the historical field was reflected in the Plio-Pleistocene paleomagnetic data compiled by Lee [1983]. Finally, we also want to test the significance of the single relatively large nonzonal term $\left(h_{2}^{1}\right)$ found by Livermore et al. [1983] in their analysis of Plio-Pleistocene data.

In analyzing the core data from equatorial latitudes [Schneider and Kent, 1988b] we found that the best fitting dipole axis fell within $1^{\circ}$ of the geographic pole for each of the four polarity chrons of the Plio-Pleistocene. We argued that these equatorial measurements (generally from within $15^{\circ}$ of the equator) should be most sensitive to any dipole tilt because $1^{\circ}$ if tilt would correspond to $2^{\circ}$ of inclination change at the equator (or a $4^{\circ}$ difference between hemispheres). Finding no significant inclination variation with longitude, we concluded that the equatorial dipole and true polar wander have been negligible over the last 5 m.y.

In a manner similar to our equatorial analysis, we can examine the variation with longitude of the larger set of core data considered here. By analogy to the definition of $\Delta$, we have analyzed the residual inclination

$$
\text { Residual } I=I \text { (observed) }-I \text { (model) }
$$

as a function of longitude, where $I$ (model) is calculated using (5) with the quadrupole and octupole terms given in Table 2. We have examined the possible variation with longitude for two separate latitudinal bands: $+15^{\circ}$ to $-15^{\circ}$ (equatorial) and $-15^{\circ}$ to $-51^{\circ}$ (southern hemisphere). Unfortunately (at least for the purposes of this deep-sea sediment study), the northern hemisphere is too populated with continents to reasonably examine variation in a northern mid-latitude band.

For the four data sets considered (equatorial Brunhes, equatorial Matuyama, southern hemisphere Brunhes, and southem hemisphere Matuyama), the best fitting sinusoids of residual inclination as a function of longitude all have rms amplitudes that are less than $2^{\circ}$ (Figure 7 and Table 3). As in our previous analysis, the equatorial results show little internal consistency in that the normal and reverse fits are approximately $180^{\circ}$ out of phase. The southern

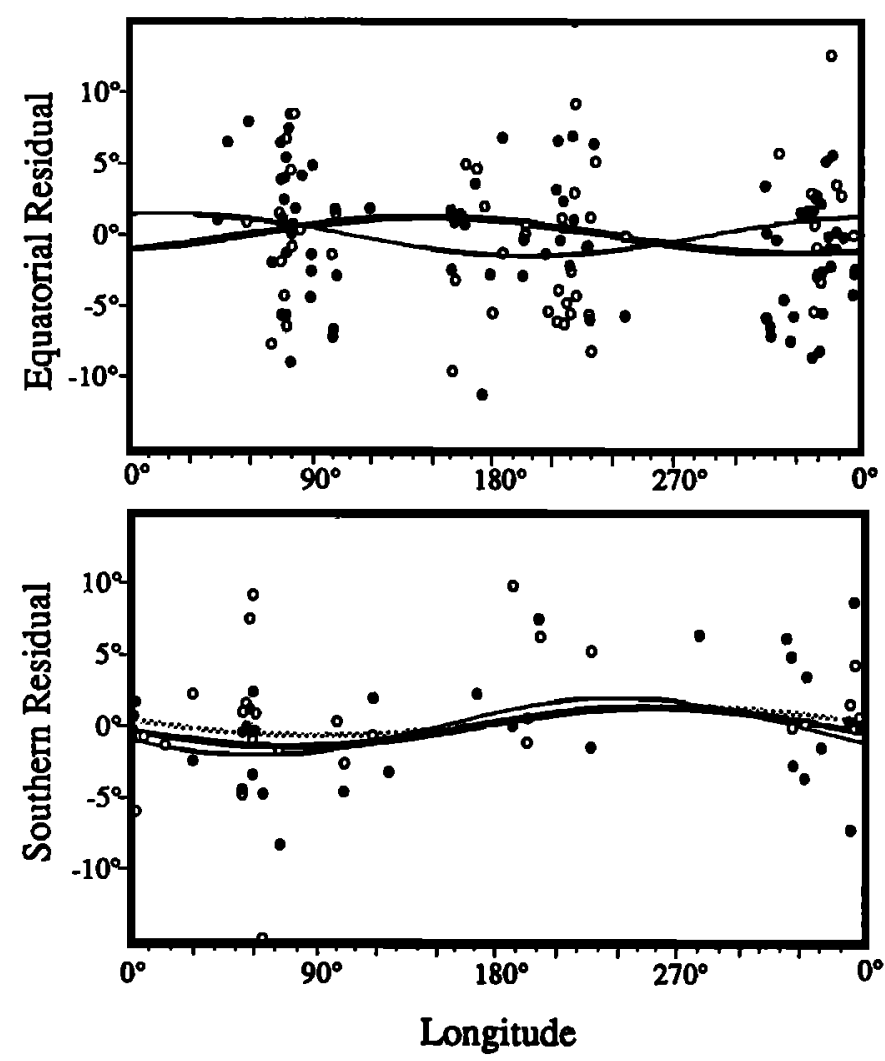

Figure 7. Residual anomaly (observed inclination minus inclination of $\mathbf{G 2}+\mathbf{G 3}$ zonal harmonic model) as a function of longiwde for equatorial $\left(-15^{\circ}\right.$ to $\left.+15^{\circ}\right)$ and southern $\left(-51^{\circ}\right.$ to $\left.-15^{\circ}\right)$ latitude bands. Solid points indicate Brunhes normal polarity chron averages; open points indicate Matuyama reverse polarity chron averages. Heavy solid curve shows best sinusoidal fit to normal polarity data; light solid curve shows best sinusoidal fit to reverse polarity data. None of the indicated sinusoids are of sufficient amplitude to be considered statistically significant (Table 3). Shaded curve in lower panel indicates the residual inclination anomaly for a field containing $3.1 \% h_{2}^{1}$ as calculated for a latitude of $27.5^{\circ} \mathrm{S}$.

TABLE 3. Sinusoidal Fits to Residual Inclination as a Function of Longitude and Ascociated Analysis of Variance Statistics

\begin{tabular}{lcrrrrr}
\hline \multicolumn{1}{c}{ Chron/Latitude } & $N$ & $\begin{array}{c}I_{p^{\prime}} \\
\text { deg }\end{array}$ & $\begin{array}{r}\text { Qd, } \\
\text { deg }\end{array}$ & $\begin{array}{c}\text { SSreg, } \\
\text { deg }\end{array}$ & $\begin{array}{c}\text { SSdev, } \\
\text { deg }\end{array}$ & $F(F$ sig) \\
\hline Brunhes/equatorial & 85 & -1.1 & 0.7 & 73.4 & 1733.1 & $1.7(3.1)$ \\
Brunhes/southern & 34 & -0.3 & -1.4 & 30.9 & 692.3 & $0.7(3.2)$ \\
Matuyama/equatorial & 54 & 1.4 & 0.5 & 71.2 & 1186.3 & $1.5(3.2)$ \\
Matuyama/southern & 28 & -1.0 & -1.8 & 71.3 & 793.3 & $1.1(3.4)$ \\
\hline
\end{tabular}

$N$, number of cores; $I_{p}$, In phase component; $Q d$, quadrature component; SSreg, sum of squares due to regression; SSdev, sum of squares due to deviations; $F(F$ sig), calculated $F$ ratio ( $F$ ratio needed for $95 \%$ significance level). 
hemisphere results appear somewhat more regular in that both the normal and the reverse polarity fits show a maximum residual $I$ near $270^{\circ} \mathrm{E}$ longitude (with a corresponding minimum near $90^{\circ} \mathrm{E}$ ). In our previous equatorial study we estimated errors numerically; here we use an analysis of variance to better gauge the significance of the best fitting sinusoids. The results of such analysis (shown also in Table 3) indicate that none of the sinusoids have sufficient amplitude to be considered statistically significant. Thus, at least on the basis of the present core data, we cannot demonstrate a low-order longitudinal variation of the time-averaged paleomagnetic field.

\section{INTERPRETATION OF ZONAL HARMONICS}

The lack of any distinct longitudinal variation supports our prior assertion that the data are well described by a zonal harmonic model, a result largely consistent with the findings of Merrill and McElhinny [1977] and Coupland and Van der Voo [1980] in their analyses of the timeaveraged field. We do note, however, that the southem hemisphere data might suggest a weak variation in longitude, with the residual inclination maximum near $270^{\circ} \mathrm{E}$. Although this variation is not statistically significant, it is interesting that the amplitude and phase of the best fitting sinusoid are in good agreement with what would be expected from the $3.1 \% h_{2}^{1}$ term determined by Livermore et al. [1983] (Figure 7).

The magnitudes of the axial quadrupole ( $G 2$ and octupole (G3) fields, which we can clearly discern here, do differ somewhat from the estimates determined by previous analyses, and these differences need to be examined. The most significant difference is seen in the octupole. Our Brunhes and Matuyama results both indicate a negative value for $G 3$ of about $-3 \%$; that is, $8 \mathrm{y}$ $g_{1}^{0}$ is negative for both normal (negative $g_{1}^{0}$ ) and reverse (positive $g_{1}^{9}$ polarity intervals. All of the previous spherical harmonic analyses mentioned above have determined positive ratios for the octupole, typically of +2 to $+3 \%$. (Note that Coupland and Van der Voo [1980], in normalizing by the absolute value of $g_{1}^{0}$, quote negative values for the octupole term. Also, the octupole results shown by Merrill and McElhinny [1977] contained an error in sign [Merrill et al., 1979] and so too, when corrected, would indicate a positive coefficient ratio for both normal and reverse polarity data.)

We speculate that the cause of this discrepancy may be a spurious shallowing of remanent inclination in the land-derived data sets. Shallowing of inclination, whether generated at the time remanence is acquired or during compaction, has been recognized since the earliest studies of sedimentary paleomagnetism [McNish and Johnson, 1983]. For example, it has been found in both laboratory redeposition experiments and in nature that the inclination of remanence in continental sediments can be considerably shallower than expected even where compaction is minimal [Tauxe and Kent, 1984]. This tendency toward shallowing of depositional remanent magnetization (DRM) is normally attributed to the rotation of magnetic grains during deposition in response to gravitational or hydrodynamic torques. Models for the shallowing of DRM by rotation of platelike grains toward horizontal [King, 1955] or by the rolling of spherical grains about horizontal axes [Griffiths et al., 1960] both predict that

$$
\tan I \text { (observed) }=f \tan I \text { (field) }
$$

where $f$ characterizes the degree of inclination error. Compaction-induced shallowing of inclination follows a similar function [Anson and Kodama, 1987].

Artificial shallowing also appears to be possible in lavas. A clear demonstration of the spurious shallowing of thermoremanent magnetization (TRM) is given by Castro and Brown [1987] in their examination of two recently erupted Hawaiian flows. Knowing the true field inclination $\left(-37^{\circ}\right)$ at the site of these modern (1950 and 1972) flows, Castro and Brown could directly determine the shallowing bias in the remanence. They argue that the shallowing they observe $\left(3^{\circ}\right.$ to $\left.6^{\circ}\right)$ is too large to be caused by internal demagnetization effects (such as those described by Coe [1979], so the mechanism for this shallowing of TRM remains unclear.

Given the demonstrated occurrence of shallowing in a variety of rock types, one must recognize that the body of published paleomagnetic results used for the various time-averaged field analyses might well contain some amount of contamination from spurious shallowing. . It has been noted [e.g., Merrill and McElhinny, 1983] that such shallowing would have an effect quite similar to that of a positive $G 3$ field (Figure 8). We therefore presume that the previous analyses of the time-averaged field show positive $G 3$ values because of contamination with spurious shallowing (characterized by an average $f$ value of about 0.9). We believe, however, that the postdepositional mechanism of remanence acquisition in deep-sea sediments may be largely free from inclination shallowing [Harrison, 1974; Kent, 1973]. Although at greater depths compaction may shallow the inclination in deep-sea sediments [Ceyala and Clement, 1988], the sediments we have studied were never buried more than $10-20 \mathrm{~m}$. Accordingly, we interpret the negative $G 3$ estimate found here (corresponding to inclinations which are steepened) as more representative of the actual paleomagnetic field.

Our estimate for the average quadrupole contribution (G2) of 0.036 generally agrees with prior spherical harmonic studies, which give 0.047 [Livermore et al., 1983], 0.063 [Coupland and Van der Voo, 1980], and 0.067 [Merrill and McElhinny, 1977] for $g_{2}^{0} / g_{1}^{0}$, and is essentially equal to the estimates we derived previously using only equatorial data from cores [Schneider and Kent, $1988 a, b]$ and from the skewness of marine magnetic anomalies [Schneider, 1988]. We suggest that the quadrupole value given here, although somewhat smaller than the estimates determined in other spherical harmonic studies, may be the more representative value because we have accounted for the effects of plate motion (which, being predominantly northward, would otherwise tend to 


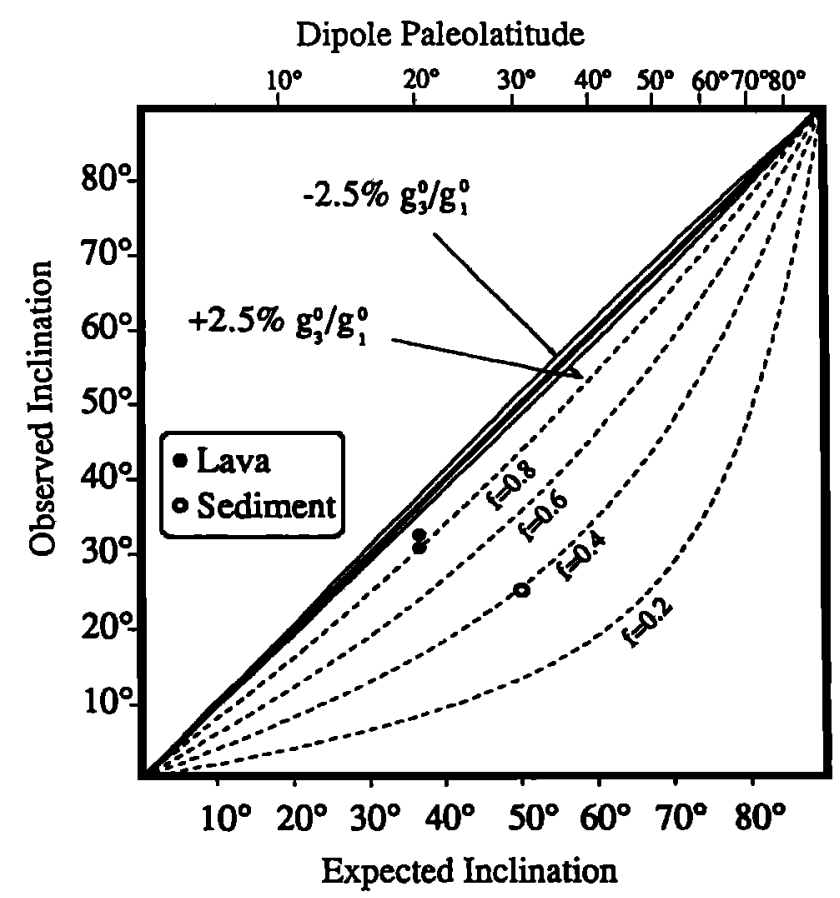

Figure 8. Comparison of positive and negative octupolar paleomagnetic field effects (solid curves) with spurious inclination error (dashed curves) calculated from the relation tan $I$ (observed) $=f \tan I$ (expected) for various values of the parameter $f$. The similarity of predicted trends suggests that previously reported positive octupole values may have resulted from slight spurious shallowing affecting the analyzed data. Examples of spurious shallowing of inclination are from Hawaiian lavas (solid points [Castro and Brown, 1987]) and from continental Siwalik sediments (open points [Tauxe and Kent, 1984]).

exaggerate the quadrupole) and because we have determined the quadrupole independently of the octupole or any spurious shallowing (which might also exaggerate the quadrupole if most data sites are located in the northern hemisphere). But whatever is the exact cause of the discrepancies between studies, the fundamental similarities should be stressed: three very different data sources, continental rocks (contributing most to the published pole listings which have been examined), deep-sea sediments (analyzed here), and oceanic basement rocks (sensed using marine magnetic anomalies), all show a small but distinct quadrupole effect which, unlike the positive octupole effects reported, cannot be attributed to spurious shallowing.

Because polarity dependence was well established in our study of equatorial cores spanning the four polarity chrons of the Plio-Pleistocene, we consider the Brunhes and Matuyama data separately in determining the configuration of the field for both normal and reverse polarity times (there are insufficient cores penetrating through the Gauss and Gilbert in the nonequatorial cores included in the global data set). As would be expected from our previous equatorial study, the quadrupole estimate is distinctly different for these two groups: the reverse polarity ratio is $0.046 \pm 0.010$. The difference between the two estimates of the octupole do not vary substantially between the opposite polarity chrons $(-0.029 \pm 0.015$ for the Brunhes and $-0.021 \pm 0.020$ for the Matuyama), so we cannot discern any polarity dependence in this component. This result contrasts with that of Merrill and McElhinny [1977], which indicated a polarity dependence over the past $5 \mathrm{~m}$.y. in both the zonal quadrupole $(0.050$ for normal compared with 0.083 for reverse) and octupole terms (0.017 for normal compared with 0.034 for reverse). Perhaps the octupole results of Merrill and McElhinny [1977] were affected by the polarity-dependent quadrupole field: the largely land-based data set analyzed in their study was probably dominated by northern hemisphere sites, and this might not have allowed for a clear separation between quadrupole and octupole contributions.

\section{GEOMAGNETIC IMPLICATIONS}

Our analysis of sediment cores confirms prior indications of polarity dependence in the quadrupole term. We have, however, found an octupole term which is of similar magnitude for normal and reverse polarity and is of opposite sign to that determined in previous nondipole field studies. The negative $G 3$ in the time-averaged field found here is in good agreement with Cox's [1975] argument that the zonal components of the present-day geomagnetic field should persist in the time-averaged field configuration: the ratio of $g_{3}^{0}$ to $g_{1}^{0}$ is presently about -0.04 , similar to the -0.03 value found in this study. (The ratio of $g_{2}^{0}$ to $g_{1}^{0}$ is presently about 0.07 .) Although the correspondence between the instantaneous and timeaveraged zonal fields is not exact, there is considerable similarity in the zonal quadrupole and octupole components (Figure 9), which suggests that the instantaneous and ime-averaged fields are closely related. We should perhaps not expect a complete correspondence for these terms, given that the instantaneous zonal coefficients have changed considerably during the past few centuries (e.g., J. Bloxham, personal communication, 1988).

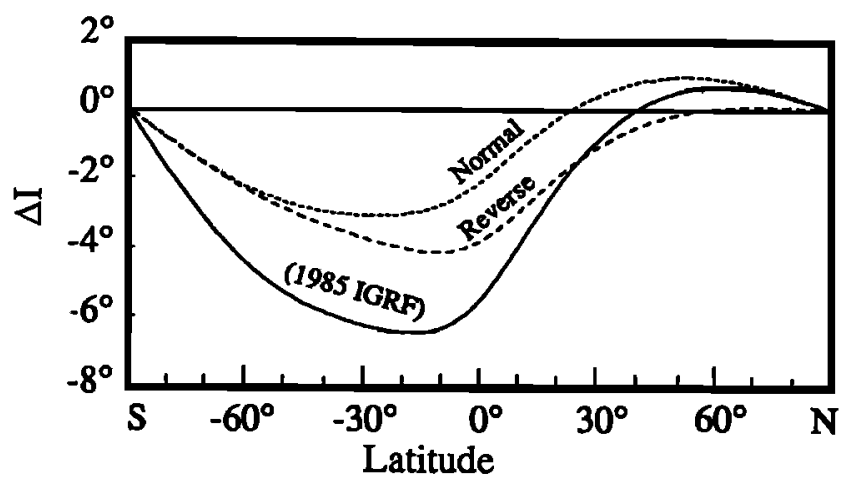

Figure 9. Inclination anomaly as a function of latitude for zonal quadrupole/octupole models of the time-averaged paleomagnetic field (dotted and dashed curves for normal and reverse polarity) presented in this study compared with the effect of the zonal quadrupole/octupole terms in the modern geomagnetic field (solid curve). 
Finding distinct polarity dependence with even symmetry (in the quadrupole) but none with odd symmetry (in the octupole) might reflect a fundamental difference in how these fields are generated in the core dynamo. It appears that the octupole completely changes sign during a transition of the main (dipole) field, while the quadrupole does not. This notion may be consistent with theoretical arguments that suggest the dynamo can be decomposed into noninteracting dipole and quadrupole families [Roberts and Stix, 1972; Merrill and McFadden, 1988]. Thus it may be reasonable to conclude that the octupole field (one of the dipole family) may be more closely linked to the main dipole than is the quadrupole field (one of the quadrupole family). Perhaps, as has been suggested [Merrill et al., 1979; Schneider and Kent, 1988a], a small quadrupole field persists that is completely unaffected by polarity reversals of the main dipole field. Such a standing quadrupole field would have opposite effect for alternate dipole polarity states, leading to the observed polarity dependence of this term.

It is not clear, however, whether the concept of a standing nondipole field describes a physically distinct phenomenon or merely gives a convenient way to express the polarity asymmetry in the time-averaged field. If a true standing field exists independently of the main reversing field, then its effects may be most obvious during polarity transitions when the main field collapses. Although Merrill et al. [1979] found little support for a true standing field source, we reviewed more recent transitional field data from equatorial sediments [Schneider and Kent, 1988a] which seemed reasonably consistent with a genuine standing field; that is, a predominance of steep positive inclinations during a transition is predicted and appears to be found. We therefore suggested that the transitional field results from these sediments might be explained by the standing quadrupole. This notion of a standing quadrupole is similar to the two axial dipole model of Pesonen and Nevanlinna [1988], which they constructed to link transitional and full-polarity directions observed by Valet and Laj [1981] in Crete: in this model a minor offset dipole remains fixed while the major geocentric dipole reverses polarity. Rochette [1989], however, cautions that such indications of a standing field recorded in sediments may result from the recording process, which might average the nonantipodal directions bounding the transitional zones. In any case, a standing field seems necessary to account for the observation of polarity dependence of the time-averaged field.

Merrill et al. [1979] consider a number of mechanisms that could generate a standing field. Because the fundamental dynamo equations are symmetrical in the sign of the magnetic field, opposite polarity states would, in principle, be expected to have time-averaged fields of opposing signs but the same overall configuration. The differing quadrupolar contribution between polarity states can be accounted for only by a standing field that is independent of the main reversing dipole. These authors argue that the most plausible source for field would be thermoelectric currents at sosannantle boundary (CMB). Although it is difficult to vediate the conditions required for such currents, the werature differences at the CMB inferred from sêisarìic "evidence could lead to appreciable thermoelectric aurouts and so might explain the polarity dependence of the paleomagnetic field [Schneider and Kent, $19886 \%$; R. T. Merrill, personal communication, 1989].

\section{TECTONIC IMPLICATIONS}

Although the theoretical understanding of these persistent nondipole fields remains vague, their practical consequences are evident: the accuracy of the paleomagnetic method used in tectonic studies can be no better than the accuracy to which the mean field is known. Although nondipole fields during the Plio-Pleistocene have amounted to only a few percent of GAD, these effects are systematic and will affect detailed tectonic studies. Because the nondipole contributions for the past $5 \mathrm{~m}$.y. are now well characterized, a more refined field model can and should be used for analyzing Pleistocene and Pliocene age results (equation (5) and Table 4). Neglecting the effects of the demonstrated quadrupole and octupole components may result in errors in paleolatitude that range up to $4^{\circ}$ for the Plio-Pleistocene.

One example where the application of a nondipole field model critically changes the interpretation of paleomagnetic data has been in the study of true polar wander. Using the conventional GAD assumption to determine pole positions from global paleomagnetic data, Morgan [1981] and Andrews [1985] suggested that rapid episodes of true polar wander had occurred during the past 5 m.y. In a reanalysis that considered the influence of the nondipole field [Schneider and Kent, 1986], we found, however, that correcting these same paleomagnetic data for nondipole effects reduced the amount of indicated true polar wander substantially. Although the positive octupole value then used to perform the nondipole correction does not match our present understanding of the time-averaged field, it appears that the positive octupole correction acted successfully to compensate for the overall tendency toward spurious shallowing that we believe is present in the continental data analyzed.

Another application of a nondipole field model to a detailed tectonic study can be found in the comparison of paleolatitudes determined from the paleomagnetism of sediments recovered from the western Indian Ocean with predictions based on the fixity of African hotspots [Schneider and Kent, 1990]. For that study, we postulated that the Plio-Pleistocene value of the quadrupole could reasonably be applied to these equatorial sediments of Neogene age. We found that the paleomagnetic inclinations could indeed be better reconciled with the northward motion of Africa determined from hotspot tracks if such a nondipole field model was used. 
TABLE 4. Paleolatitude as a Function of Inclination for Alternative Field Models

\begin{tabular}{|c|c|c|c|c|c|}
\hline $\begin{array}{l}\text { Inclination, } \\
\text { deg }\end{array}$ & $\begin{array}{c}\text { Dipole } \\
\text { pLat, deg }\end{array}$ & $\begin{array}{c}\text { Nondipole } \\
\text { pLat }(N+R) \text {, deg }\end{array}$ & $\begin{array}{c}\text { Nondipole } \\
\text { pLat }(N), \text { deg }\end{array}$ & $\begin{array}{l}\text { Nondipole } \\
\text { PLat }(R), \text { deg }\end{array}$ & $\begin{array}{c}\text { Paleolatitude } \\
\text { Error }\end{array}$ \\
\hline-90.0 & -90.0 & -90.0 & -90.0 & -90.0 & 0.0 \\
\hline-85.0 & -80.1 & -78.1 & -78.1 & -78.1 & 2.0 \\
\hline-80.0 & -70.6 & -67.3 & -67.3 & -67.3 & 3.3 \\
\hline-75.0 & -61.8 & -57.9 & -58.0 & -57.8 & 3.9 \\
\hline-70.0 & -53.9 & -50.0 & -50.1 & -49.8 & 3.9 \\
\hline-65.0 & -47.0 & -43.2 & -43.4 & -43.0 & 3.8 \\
\hline-60.0 & -40.9 & -37.4 & -37.6 & -37.1 & 3.5 \\
\hline-55.0 & -35.5 & -32.3 & -32.6 & -32.0 & 3.2 \\
\hline-50.0 & -30.8 & -27.8 & -28.1 & -27.5 & 3.0 \\
\hline-45.0 & -26.6 & -23.9 & -24.2 & -23.5 & 2.7 \\
\hline-40.0 & -22.8 & -20.3 & -20.6 & -20.0 & 2.5 \\
\hline-35.0 & -19.3 & -17.0 & -17.3 & -16.7 & 2.3 \\
\hline-30.0 & -16.1 & -14.0 & -14.3 & -13.6 & 2.1 \\
\hline-25.0 & -13.1 & -11.2 & -11.5 & -10.8 & 1.9 \\
\hline-20.0 & -10.3 & -8.5 & -8.8 & -8.1 & 1.8 \\
\hline-15.0 & -7.6 & -5.9 & -6.3 & -5.5 & 1.7 \\
\hline-10.0 & -5.0 & -3.4 & -3.8 & -3.0 & 1.6 \\
\hline-5.0 & -2.5 & -1.0 & -1.4 & -0.6 & 1.5 \\
\hline 0.0 & 0.0 & 1.4 & 1.0 & 1.9 & 1.4 \\
\hline 5.0 & 2.5 & 3.9 & 3.4 & 4.3 & 1.4 \\
\hline 10.0 & 5.0 & 6.3 & 5.9 & 6.7 & 1.3 \\
\hline 15.0 & 7.6 & 8.8 & 8.4 & 9.3 & 1.2 \\
\hline 20.0 & 10.3 & 11.4 & 10.9 & 11.9 & 1.1 \\
\hline 25.0 & 13.1 & 14.1 & 13.6 & 14.6 & 1.0 \\
\hline 30.0 & 16.1 & 17.0 & 16.5 & 17.5 & 0.9 \\
\hline 35.0 & 19.3 & 20.1 & 19.5 & 20.6 & 0.8 \\
\hline 40.0 & 22.8 & 23.4 & 22.8 & 23.9 & 0.6 \\
\hline 45.0 & 26.6 & 27.0 & 26.4 & 27.6 & 0.4 \\
\hline 50.0 & 30.8 & 31.1 & 30.5 & 31.7 & 0.3 \\
\hline 55.0 & 35.5 & 35.6 & 34.9 & 36.3 & 0.1 \\
\hline 60.0 & 40.9 & 40.8 & 40.0 & 41.4 & -0.1 \\
\hline 65.0 & 47.0 & 46.6 & 45.9 & 47.3 & -0.4 \\
\hline 70.0 & 53.9 & 53.3 & 52.6 & 54.1 & -0.6 \\
\hline 75.0 & 61.8 & 61.1 & 60.4 & 61.8 & -0.7 \\
\hline 80.0 & 70.6 & 69.9 & 69.3 & 70.4 & -0.7 \\
\hline 85.0 & 80.1 & 79.6 & 79.3 & 79.9 & -0.5 \\
\hline 90.0 & 90.0 & 90.0 & 90.0 & 90.0 & 0.0 \\
\hline
\end{tabular}

$(N+R)$ calculated on the basis of average values for zonal quadrupole $(0.036)$ and octupole $(-0.025)$. $(N)$ and $(R)$ calculated on the basis of normal and reverse field values shown in Table 2. Paleolatitude error shows difference between $(N+R)$ nondipole and dipole models.

\section{PRE-PLIOCENE NONDIPOLE FIELDS}

Although substantial differences occur in the average field between normal and reverse polarity times, our Plio-Pleistocene age results (at least from equatorial latitudes) do not show any appreciable changes with time. This finding attests to some stability in the average field configuration, but it by no means indicates that the relative contribution of the nondipole components is necessarily constant. Indeed, there are distinct changes in another geomagnetic field parameter, reversal frequency, that occur over the long term but would not be predicted were the available record of reversals only $5 \mathrm{~m} . \mathrm{y}$. long. Thus very long term variation in nondipole field content also would not be unexpected.

It has, of course, been quite difficult to estimate the harmonic composition of the field for pre-Pliocene times. One must contend with a relative sparsity of reliable paleomagnetic data (compared to the Plio-Pleistocene) as well as with the need to correct for plate motions. The usual route of analysis is to use an absolute plate motion model derived from fracture zone trends, marine magnetic anomalies, and hotspot tracks. This absolute (hotspot) reference frame then can be compared with paleomagnetic 
observations. Errors in the relative plate motion circuit used, as well as the possibility of systematic departures between the hotspot and paleomagnetic references [Morgan, 1981; Harrison and Lindt, 1982; Livermore et al., 1984; Andrews, 1985], further complicate attempts to gauge the magnitude of nondipole effects.

Despite these formidable problems, two studies have attempted to estimate the zonal nondipole field contribution since the Mesozoic [Coupland and Van der Voo, 1980; Livermore et al., 1984]. Being limited to published pole listings, however, neither of these studies could readily separate normal and reverse polarity results. Coupland and Van der Voo [1980] attempted to fit both quadrupole and octupole fields, while Livermore et al. [1984] considered it unreasonable to describe more than the quadrupole for times prior to $5 \mathrm{Ma}$. (As mentioned, Coupland and Van der Voo [1980] normalized their estimates of spherical harmonic coefficients to the absolute value of $g_{1}^{0}$, thus introducing a difference in sign compared with other studies. Consequently, in considering the results of Coupland and Van der Voo [1980], we have inverted the sign of the nondipole coefficients to allow a more direct comparison with other estimates.)

Both of these studies found that nondipole field components could, at times, be larger than $10 \%$ of the dipole. The results from these two separate analyses agree reasonably for the Tertiary but differ for earlier times. One example of such disagreement is that Coupland and Van der Voo [1980] find that a dipole + quadrupole model (i.e., octupole set to zero) gives a relatively large positive quadrupole/dipole ratio for the late Cretaceous, while Livermore et al. [1984] find a large negative ratio for the same interval. This difference in quadrupole estimates, amounting to more than $20 \%$ of the dipole field, is substantial.

The Tertiary age results of Coupland and Van der Voo [1980] also show the problem of nonorthogonality of the harmonic functions caused by a poor data distribution. Using a dipole + quadrupole model, their estimate of the quadrupole is about $+10 \%$ from the middle Eocene to early Miocene; however, using a dipole + quadrupole + octupole model, they find for the same period a smaller (5\%) quadrupole of variable sign and a large ( $>10 \%)$ octupole. The estimates of these two terms are clearly not independent. Recognizing that this problem arose from errors in the relatively sparse southem hemisphere data, Livermore et al. [1984] chose to limit this pre-Pliocene analysis to the determination of the axial quadrupole. Although this simpler approach avoided obvious inconsistencies in modeling, it remains likely that the quadrupole estimates they determined may have been influenced by octupole fields and possibly also by spurious shallowing in the data analyzed.

Despite the ambiguity in relative importance of the quadrupole and octupole terms, the pre-Pliocene nondipole analyses suggest that these spherical harmonic terms may well have been 2 or 3 times larger in the early Tertiary compared with the Plio-Pleistocene. Relatively large Tertiary nondipole fields appear also to be supported by specific tests with more recent and independent data [Kent and Schneider, 1989] which, although showing little or no octupole contribution, indicate a substantial ( $10 \%)$ positive quadrupole field for the earliest Tertiary.

The inherent requirement for a broad data distribution and accurate plate motion corrections will make the absolute magnitude of the nondipole field for pre-Pliocene times difficult to obtain. Nevertheless, it should be possible to determine the behavior of the standing field more readily. The standing field will give rise to a polarity dependence of paleomagnetic directions which can be easily measured by the degree to which normal and reverse directions depart from being antipodal at any given location. Indeed, several observations of such polarity dependence have been noted in paleomagnetic investigations of pre-Pliocene age rocks. Nevanlinna and Pesonen [1983] noted a large polarity dependence in the location of Precambrian paleomagnetic pole positions for North America which they attributed to the geomagnetic field. Diehl et al. [1988] also found a distinct ( $8^{\circ}$ ) polarity dependence of directions in their results from the Oligocene Datil-Mogollon volcanic field in New Mexico which they attributed to a nondipole source. In addition, Witte and Kent [1989] found slightly nonantipodal directions in Triassic rocks from the Newark Basin which could not be easily explained by a younger secondary overprint. All these results certainly demand careful scrutiny so as not to confuse the effects of contamination by secondary magnetization with a true polarity dependence of the field; however, such observations may eventually give a coherent picture of the evolution of the standing nondipole field through time.

\section{CONCLUSIONS}

Although the geocentric axial dipole provides a good first-order model of the time-averaged geomagnetic field, the precision available from paleomagnetic data representing the past few million years is clearly capable of resolving second-order features. The important components of the mean field are largely axially symmetric, with zonal quadrupole $\left(g_{2}^{0}\right)$ and zonal octupole $\left(g_{3}^{0}\right)$ contributions that are a few percent of the geocentric axial dipole $\left(g_{1}^{0}\right)$. No statistically significant nonzonal effects can be discerned with the deep-sea sediment data presently at hand; however, these data are not inconsistent with the small equatorial quadrupole field suggested by Livermore et al. [1983].

In contrast to previous analyses our study of deep-sea sediments indicates that the time-averaged zonal octupole to dipole ratio is negative, rather than positive. We presume that the body of paleomagnetic results previously considered may be affected by inclination errors, which 
give rise to a positive octupole ratio. Our finding of a negative ratio indicates that the time-averaged field may be quite similar to the low-degree zonal configuration of the present-day instantaneous field. Note that the presence of any significant octupole component is not consistent with the original offset dipole model of Wilson [Wilson and Ade-Hall, 1970] which, to first order, describes only the addition of an axial quadrupole contribution to the geocentric axial dipole.

Our results confirm previous indications that the quadrupole varies in relative magnitude with polarity of the main dipole. We find, however, that the octupole has a more constant contribution relative to the dipole. These observations suggest that the dipole and octupole fields may be genetically linked, and so lend support to dynamo models in which the dipole and quadrupole family of terms are considered separate.

The lack of any clear secular trend over the PlioPleistocene suggests that the zonal field model may also be appropriate for somewhat earlier times. Estimation of the exact configuration of the paleomagnetic field for intervals before the Pliocene demands significant refinement, but there are already some indications of larger $(-10 \%)$ nondipole contributions at times in the early Tertiary. Continued investigation of the evolution of the polarity asymmetry of the paleomagnetic field, as well as the absolute magnitude of its nondipole components, should improve the accuracy of paleomagnetic studies applied to tectonics and also increase our understanding of the behavior of the geodynamo. 
TABLE A1. Location and Length of Piston Cores Analyzed

\begin{tabular}{|c|c|c|c|c|c|c|}
\hline Core & Plate & $\begin{array}{l}\text { Latitude, } \\
\text { deg }\end{array}$ & $\begin{array}{l}\text { Longitude, } \\
\text { deg }\end{array}$ & $\begin{array}{c}\text { Core Length, } \\
\mathrm{cm}\end{array}$ & $\begin{array}{c}\text { Water Depth, } \\
\text { m }\end{array}$ & \\
\hline KN09-057 & AFRC & 8.63 & -22.03 & 2353 & 4479 & \\
\hline MD81-369 & INDI & -10.05 & 79.80 & 1772 & 5293 & \\
\hline MD81-375 & INDI & -12.78 & 77.77 & 1750 & 5279 & \\
\hline RC08-052 & INDI & -41.10 & 101.42 & 1103 & 4393 & \\
\hline RC08-053 & INDI & -39.38 & 104.37 & 965 & 4429 & \\
\hline RC08-061 & INDI & -46.53 & 125.57 & 388 & 4254 & \\
\hline RC08-080 & PCFC & -48.30 & -162.90 & 895 & 4997 & \\
\hline RC08-081 & PCFC & -47.95 & -159.05 & 1285 & 5130 & \\
\hline RC09-114 & PCFC & -33.68 & -165.05 & 1032 & 5453 & \\
\hline RC09-119 & PCFC & -23.38 & -171.98 & 1012 & 5693 & \\
\hline RC09-125 & PCFC & -31.45 & 170.22 & 958 & 4125 & \\
\hline RC10-095 & PCFC & 3.52 & 230.28 & 1705 & 4471 & \\
\hline RC10-159 & PCFC & 31.22 & 162.32 & 1776 & 5894 & \\
\hline RC10-160 & PCFC & 32.48 & 159.83 & 1245 & 4621 & \\
\hline RC10-161 & PCFC & 33.08 & 158.00 & 1166 & 3587 & \\
\hline RC10-164 & PCFC & 31.73 & 157.50 & 969 & 3766 & \\
\hline RC10-167 & PCFC & 33.40 & 150.38 & 1835 & 6092 & \\
\hline RC10-169 & PCFC & 32.52 & 151.07 & 1142 & 5740 & \\
\hline RC10-171 & PCFC & 32.48 & 153.03 & 1219 & 5544 & 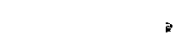 \\
\hline RC10-174 & PCFC & 32.07 & 157.58 & 866 & 3191 & . \\
\hline RC10-175 & PCFC & 34.58 & 159.17 & 868 & 4014 & \\
\hline RC10-178 & PCFC & 37.80 & 172.33 & 1072 & 5808 & \\
\hline RC10-179 & PCFC & 39.63 & 173.72 & 995 & 4312 & \\
\hline RC10-181 & PCFC & 44.08 & 176.83 & 1205 & 5698 & \\
\hline RC10-182 & PCFC & 45.62 & 177.87 & 1173 & 5561 & \\
\hline RC10-203 & PCFC & 41.70 & -171.95 & 1186 & 5883 & \\
\hline RC11-034 & SOAM & -33.32 & -33.62 & 1055 & 4235 & \\
\hline RC11-104 & ANTA & -40.92 & 57.65 & 1126 & 4885 & \\
\hline RC11-105 & ANTA & -38.78 & 58.83 & 1080 & 5256 & \\
\hline RC11-106 & AFRC & -34.33 & 54.22 & 768 & 4212 & \\
\hline RC11-166 & PCFC & 43.77 & 171.23 & 1115 & 5841 & \\
\hline RC11-170 & PCFC & 44.48 & -163.35 & 1023 & 5451 & \\
\hline RC11-171 & PCFC & 46.60 & -159.66 & 1166 & 5167 & \\
\hline RC11-193 & PCFC & 39.95 & -140.05 & 1234 & 4748 & \\
\hline RC11-209 & PCFC & 3.65 & 219.93 & 1506 & 4400 & . \\
\hline RC11-213 & PCFC & -6.13 & 219.15 & 1080 & 4343 & \\
\hline RC11-227 & PCFC & -5.98 & 245.38 & 1058 & 4158 & \\
\hline RC12-063 & PCFC & 5.97 & 217.35 & 1558 & 4949 & \\
\hline RC12-065 & PCFC & 4.65 & 215.03 & 2426 & 4868 & \\
\hline RC12-066 & PCFC & 2.62 & 211.78 & 2800 & 4755 & \\
\hline RC12-083 & PCFC & 3.69 & 194.95 & 1508 & 5351 & \\
\hline RC12-084 & PCFC & 2.33 & 194.80 & 2230 & 5365 & \\
\hline RC12-224 & PCFC & -51.21 & -133.68 & 1098 & 4663 & \\
\hline RC12-299 & AFRC & -34.08 & -1.00 & 948 & 4296 & \\
\hline RC12-320 & AFRC & -6.60 & 47.80 & 980 & 4784 & \\
\hline RC12-327 & AFRC & -1.73 & 57.83 & 1598 & 4446 & \\
\hline RC12-331 & INDI & -2.50 & 69.87 & 846 & 3941 & \\
\hline RC12-333 & INDI & 0.80 & 76.17 & 1032 & 4233 & \\
\hline RC12-334 & INDI & 2.40 & 77.27 & 1013 & 4217 & \\
\hline RC12-339 & INDI & 9.13 & 90.03 & 824 & 3010 & \\
\hline RC12-340 & INDI & 12.70 & 90.02 & 690 & 3012 & \\
\hline RC12-341 & INDI & 13.05 & 89.58 & 1099 & 2988 & \\
\hline RC13-210 & AFRC & -9.15 & -10.62 & 1206 & 3658 & \\
\hline RC13-212 & AFRC & $\rightarrow .50$ & -7.90 & 1035 & 3952 & \\
\hline RC13-213 & AFRC & -10.48 & -2.40 & 1165 & 5158 & \\
\hline
\end{tabular}


TABLE A1. (continued)

\begin{tabular}{|c|c|c|c|c|c|}
\hline Core & Plate & $\begin{array}{l}\text { Latitude, } \\
\text { deg }\end{array}$ & $\begin{array}{l}\text { Longitude, } \\
\text { deg }\end{array}$ & $\begin{array}{c}\text { Core Length, } \\
\mathrm{cm}\end{array}$ & $\begin{array}{c}\text { Water Depth, } \\
m\end{array}$ \\
\hline RC13-231 & AFRC & -27.07 & 5.32 & 1096 & 4217 \\
\hline RC13-238 & AFRC & -30.92 & -3.15 & 1170 & 4544 \\
\hline RC13-241 & AFRC & -35.60 & -6.72 & 682 & 4107 \\
\hline RC13-277 & AFRC & -44.57 & 15.77 & 1756 & 4877 \\
\hline RC14-013 & ANTA & -37.38 & 59.32 & 2404 & 5128 \\
\hline RC14-014 & ANTA & -35.92 & 59.97 & 2588 & 4916 \\
\hline RC14-019 & AFRC & -17.57 & 63.55 & 1620 & 3568 \\
\hline RC14-022 & INDI & -11.47 & 75.15 & 1698 & 5276 \\
\hline RC14-023 & INDI & -9.17 & 76.67 & 1175 & 5376 \\
\hline RC14-024 & INDI & -6.63 & 79.43 & 1215 & 5183 \\
\hline RC14-046 & INDI & -7.82 & 100.00 & 1415 & 5566 \\
\hline RC14-083 & PCFC & 13.08 & 118.50 & 1333 & 3166 \\
\hline RC14-103 & PCFC & 44.03 & 152.94 & 1528 & 5365 \\
\hline RC14-120 & NOAM & 55.77 & -170.43 & 1680 & 1973 \\
\hline RC15-020 & PCFC & 5.02 & 228.05 & 1635 & 4241 \\
\hline RC15-021 & PCFC & 1.55 & 227.02 & 2106 & 4409 \\
\hline RC16-055 & SOAM & 10.38 & -45.32 & 1059 & 4763 \\
\hline RC16-066 & SOAM & -0.75 & -36.62 & 1068 & 4424 \\
\hline RC16-076 & SOAM & -13.28 & -16.27 & 898 & 3658 \\
\hline RC16-077 & AFRC & -12.65 & -13.43 & 917 & 3404 \\
\hline RC16-166 & SOAM & -0.48 & -43.08 & 1030 & 3199 \\
\hline RC17-083 & AFRC & -31.83 & 54.10 & 1142 & 4128 \\
\hline RC17-176 & PCFC & 3.75 & 158.77 & 1575 & 3156 \\
\hline VM12-018 & SOAM & -28.70 & -34.50 & 1078 & 4021 \\
\hline VM16-042 & AFRC & -29.10 & 0.33 & 834 & 4510 \\
\hline VM16-057 & AFRC & -45.23 & 29.48 & 1255 & 5289 \\
\hline VM16-070 & AFRC & -32.10 & 55.85 & 863 & 4649 \\
\hline VM16-075 & AFRC & -22.22 & 58.38 & 1256 & 4766 \\
\hline VM16-076 & AFRC & -25.15 & 59.90 & 1193 & 5316 \\
\hline VM17-058 & ANTA & -49.42 & -78.76 & 1225 & 3863 \\
\hline VM18-166 & SOAM & -34.98 & -27.12 & 1116 & 4527 \\
\hline VM18-168 & SOAM & -32.17 & -20.17 & 626 & 4251 \\
\hline VM18-177 & AFRC & -31.47 & 0.08 & 552 & 4425 \\
\hline VM19-153 & INDI & -8.85 & 102.12 & 1232 & 5433 \\
\hline VM19-154 & INDI & -11.41 & 101.40 & 1951 & 4964 \\
\hline VM19-156 & INDI & -14.63 & 101.33 & 1204 & 5363 \\
\hline VM19-171 & INDI & -7.07 & 80.77 & 1138 & 5053 \\
\hline VM19-203 & AFRC & -9.47 & 43.32 & 1324 & 3651 \\
\hline VM19-300 & AFRC & 6.88 & -19.47 & 1051 & 4263 \\
\hline VM19-301 & AFRC & 8.30 & -22.75 & 1309 & 4724 \\
\hline VM19-302 & AFRC & 10.25 & -25.37 & 1113 & 5583 \\
\hline VM20-065 & PCFC & 25.85 & -153.20 & 527 & 5363 \\
\hline VM20-074 & PCFC & 41.07 & -132.37 & 995 & 3749 \\
\hline VM20-078 & PCFC & 47.25 & -131.03 & 1076 & 2983 \\
\hline VM20-080 & PCFC & 46.50 & -135.00 & 1096 & 3801 \\
\hline VM20-085 & PCFC & 44.90 & -143.62 & 857 & 3817 \\
\hline VM20-087 & PCFC & 41.80 & -149.92 & 948 & 4819 \\
\hline VM20-088 & PCFC & 40.18 & -151.65 & 1164 & 5081 \\
\hline VM20-091 & PCFC & 37.30 & -157.70 & 656 & 5863 \\
\hline VM20-092 & PCFC & 36.30 & -159.63 & 1070 & 5764 \\
\hline VM20-094 & PCFC & 34.60 & -163.23 & 1076 & 5993 \\
\hline VM20-097 & PCFC & 32.07 & -168.73 & 1067 & 5841 \\
\hline VM20-098 & PCFC & 31.17 & -170.58 & 1242 & 5673 \\
\hline VM20-102 & PCFC & 31.18 & -177.82 & 1234 & 5216 \\
\hline VM20-105 & PCFC & 39.00 & -178.28 & 1266 & 5336 \\
\hline VM20-107 & PCFC & 43.40 & -178.87 & 1304 & 5872 \\
\hline VM20-108 & PCFC & 45.45 & -179.24 & 1748 & 5625 \\
\hline
\end{tabular}


TABLE 1. (continued)

\begin{tabular}{|c|c|c|c|c|c|}
\hline Core & Plate & $\begin{array}{l}\text { Latitude, } \\
\text { deg }\end{array}$ & $\begin{array}{l}\text { Longitude, } \\
\text { deg }\end{array}$ & $\begin{array}{c}\text { Core Length, } \\
\mathrm{cm}\end{array}$ & $\underset{m}{\text { Water Depth, }}$ \\
\hline VM20-109 & PCFC & 47.32 & -179.65 & 1501 & 5629 \\
\hline VM20-119 & PCFC & 47.95 & 168.78 & 1203 & 2739 \\
\hline VM20-167 & INDI & -21.05 & 72.50 & 622 & 3634 \\
\hline VM20-184 & AFRC & -25.80 & 53.68 & 1958 & 5031 \\
\hline VM20-234 & AFRC & 5.32 & -33.03 & 921 & 3133 \\
\hline VM21-073 & PCFC & 29.47 & 154.60 & 1027 & 5872 \\
\hline VM21-074 & PCFC & 29.85 & 150.83 & 1143 & 6015 \\
\hline VM21-075 & PCFC & 30.07 & 147.68 & 912 & 6119 \\
\hline VM21-076 & PCFC & 30.42 & 144.50 & 940 & 5916 \\
\hline VM21-087 & PCFC & 27.88 & 146.58 & 1330 & 5879 \\
\hline VM21-089 & PCFC & 23.58 & 145.65 & 1048 & 5821 \\
\hline VM21-139 & PCFC & 27.78 & 144.30 & 1215 & 6009 \\
\hline VM21-140 & PCFC & 28.55 & 146.88 & 584 & 5949 \\
\hline VM21-141 & PCFC & 30.80 & 154.07 & 662 & 5821 \\
\hline VM21-142 & PCFC & 31.58 & 156.42 & 1292 & 4241 \\
\hline VM21-144 & PCFC & 32.68 & 160.02 & 1330 & 4931 \\
\hline VM21-145 & PCFC & 34.05 & 164.83 & 1300 & 6088 \\
\hline VM21-146 & PCFC & 37.68 & 163.03 & 1245 & 3968 \\
\hline VM21-148 & PCFC & 42.08 & 160.60 & 5477 & 1967 \\
\hline VM21-150 & PCFC & 48.00 & 162.02 & 1297 & 5416 \\
\hline VM21-171 & PCFC & 49.88 & -164.95 & 1262 & 5013 \\
\hline VM21-172 & PCFC & 47.67 & -164.35 & 1206 & 5198 \\
\hline VM21-173 & PCFC & 44.37 & -163.55 & 1290 & 5493 \\
\hline VM21-175 & PCFC & 38.37 & -161.10 & 3009 & 5654 \\
\hline VM22-161 & AFRC & -27.43 & 1.47 & 1230 & 4691 \\
\hline VM22-168 & AFRC & -17.47 & -5.18 & 935 & 4625 \\
\hline VM22-173 & AFRC & -12.38 & -10.15 & 983 & 3878 \\
\hline VM22-174 & AFRC & -10.07 & -12.82 & 1670 & 2630 \\
\hline VM22-175 & SOAM & -8.77 & -14.28 & 1740 & 2950 \\
\hline VM22-177 & SOAM & -7.75 & -14.60 & 1050 & 3290 \\
\hline VM22-182 & SOAM & -0.53 & -17.27 & 1070 & $3614-3937$ \\
\hline VM22-185 & AFRC & 2.57 & -19.23 & 1039 & 4587 \\
\hline VM22-188 & AFRC & 4.67 & -20.92 & 1140 & 2600 \\
\hline VM22-192 & AFRC & 7.80 & -21.40 & 1045 & 3416 \\
\hline VM22-230 & NOAM & 32.65 & -52.30 & 1370 & 5048 \\
\hline VM24-054 & PCFC & 1.85 & 228.30 & 1718 & 4479 \\
\hline VM24-058 & PCFC & 2.27 & 218.33 & 1692 & 4490 \\
\hline VM24-059 & PCFC & 2.57 & 214.47 & 1747 & 4662 \\
\hline VM24-060 & PCFC & 2.80 & 211.00 & 1786 & 4859 \\
\hline VM24-062 & PCFC & 3.07 & 206.42 & 1808 & 4834 \\
\hline VM24-104 & PCFC & 4.85 & 170.92 & 1071 & 4501 \\
\hline VM24-107 & PCFC & 2.07 & 165.32 & 1680 & 4160 \\
\hline VM24-221 & AFRC & -32.03 & -2.82 & 1059 & 4204 \\
\hline VM24-240 & SOAM & -31.73 & -28.20 & 949 & 4327 \\
\hline VM25-044 & SOAM & 11.50 & -45.15 & 1003 & 4049 \\
\hline VM25-046 & SOAM & 9.32 & -43.00 & 954 & 4310 \\
\hline VM25-065 & SOAM & 2.32 & -45.90 & 842 & 3524 \\
\hline VM26-049 & AFRC & 5.83 & -17.87 & 882 & 4621 \\
\hline VM26-051 & AFRC & 6.03 & -18.25 & 903 & 4572 \\
\hline VM26-083 & SOAM & -29.30 & -37.25 & 733 & 3878 \\
\hline VM26-098 & SOAM & -2.18 & -31.07 & 946 & 4667 \\
\hline VM26-102 & SOAM & -0.38 & -39.13 & 1062 & 4301 \\
\hline VM27-180 & AFRC & 3.33 & -21.00 & 1117 & 4468 \\
\hline VM27-239 & AFRC & -7.83 & -1.52 & 1224 & 4464 \\
\hline VM28-179 & PCFC & 4.62 & 220.40 & 2081 & 4502 \\
\hline VM28-185 & PCFC & 2.92 & 213.33 & 2144 & 4656 \\
\hline VM28-202 & PCFC & 1.73 & 183.80 & 2120 & 5391 \\
\hline VM28-205 & PCFC & 3.62 & 178.43 & 2246 & 5568 \\
\hline
\end{tabular}


TABLE 1. (continued)

\begin{tabular}{clrrrrr}
\hline Core & Plate & $\begin{array}{c}\text { Latitude, } \\
\text { deg }\end{array}$ & $\begin{array}{c}\text { Longitude, } \\
\text { deg }\end{array}$ & $\begin{array}{c}\text { Core Length, } \\
\text { cm }\end{array}$ & $\begin{array}{c}\text { Water Depth, } \\
\boldsymbol{m}\end{array}$ \\
\hline VM28-222 & PCFC & -11.32 & 174.53 & 1216 & 2933 \\
VM28-237 & PCFC & -0.92 & 163.27 & 1403 & 4427 \\
VM28-238 & PCFC & 1.02 & 160.48 & 1609 & 3120 \\
VM28-239 & PCFC & 3.25 & 159.18 & 2102 & 3490 \\
VM28-355 & INDI & -10.45 & 100.52 & 1248 & 5066 \\
VM29-030 & INDI & 3.08 & 76.25 & 1320 & 3651 \\
VM29-034 & INDI & -5.35 & 74.40 & 1020 & 4762 \\
VM29-039 & INDI & -7.70 & 77.38 & 1165 & 5082 \\
VM29-040 & INDI & -10.48 & 78.05 & 1788 & 5325 \\
VM29-043 & INDI & -12.33 & 75.08 & 1682 & 5150 \\
VM30-036 & AFRC & 5.35 & -27.32 & 1586 & 4245 \\
VM30-045 & AFRC & 6.30 & -19.93 & 1715 & 3568 \\
VM33-014 & INDI & -43.50 & 118.52 & 868 & 4423 \\
VM33-054 & INDI & -11.02 & 84.68 & 960 & 4907 \\
VM33-055 & INDI & -4.73 & 81.70 & 964 & 4891 \\
VM34-053 & INDI & -6.12 & 89.58 & 556 & 3808 \\
\hline
\end{tabular}

Plate designations are AFRC, African; INDI, Indian; PCFC, Pacific; SOAM,

South American; ANTA, Antarctic; NOAM, North American.

TABLE A2. Brunhes Age (Normal Polarity) Data Set

\begin{tabular}{|c|c|c|c|c|c|c|c|c|}
\hline Core & $\begin{array}{c}\text { pLat, } \\
\text { deg }\end{array}$ & $\begin{array}{c}\text { pLon, } \\
\text { deg }\end{array}$ & $n$ & $\begin{array}{c}\text { Mean } \\
\text { Age, Ma }\end{array}$ & $\begin{array}{l}\text { Incl. } \\
\text { deg }\end{array}$ & $\begin{array}{r}\Delta, \\
\operatorname{deg}\end{array}$ & $\begin{array}{l}\sigma \\
\text { deg }\end{array}$ & $\begin{array}{l}\alpha_{95} \\
\text { deg }\end{array}$ \\
\hline KN09-057 & 8.6 & 338.0 & 17 & 0.45 & 7.0 & -9.9 & 7.6 & 4.8 \\
\hline MD81-369 & -10.3 & 79.6 & 6 & 0.57 & -31.7 & -11.7 & 8.4 & 10.1 \\
\hline RC08-052 & -41.4 & 101.2 & 27 & 0.43 & -48.6 & 11.8 & 8.2 & 4.0 \\
\hline RC08-053 & -39.8 & 104.1 & 8 & 0.63 & -66.6 & -7.6 & 6.5 & 6.4 \\
\hline RC08-061 & -46.5 & 125.6 & 8 & -- & -70.6 & -6.0 & 7.1 & 7.1 \\
\hline RC08-081 & -48.2 & 201.4 & 12 & 0.48 & -61.2 & 4.7 & 5.6 & 4.3 \\
\hline RC09-114 & -33.9 & 195.4 & 62 & 0.45 & -55.8 & -2.5 & 9.5 & 3.0 \\
\hline RC09-119 & -23.6 & 188.4 & 30 & 0.40 & -44.1 & -3.0 & 6.3 & 2.9 \\
\hline RC09-125 & -31.4 & 170.2 & 29 & -- & -51.5 & -0.8 & 8.9 & 4.2 \\
\hline RC10-095 & 3.4 & 230.6 & 51 & 0.42 & 11.3 & 4.6 & 9.0 & 3.2 \\
\hline RC10-159 & 31.0 & 162.9 & 11 & 0.59 & 46.7 & -3.5 & 5.4 & 4.3 \\
\hline RC10-160 & 32.3 & 160.3 & 42 & 0.45 & 52.9 & 1.2 & 4.7 & 1.8 \\
\hline RC10-161 & 32.9 & 158.5 & 23 & 0.47 & 51.9 & -0.4 & 4.5 & 2.4 \\
\hline RC10-164 & 31.5 & 158.0 & 11 & 0.55 & 52.9 & 2.1 & 3.1 & 2.5 \\
\hline RC10-167 & 33.3 & 150.8 & 406 & 0.39 & 52.0 & -0.7 & 7.1 & 0.9 \\
\hline RC10-169 & 32.5 & 151.1 & 91 & -- & 57.0 & 5.1 & 7.9 & 2.1 \\
\hline RC10-171 & 32.3 & 153.5 & 47 & 0.44 & 54.5 & 2.8 & 6.8 & 2.5 \\
\hline RC10-174 & 31.9 & 158.0 & 61 & 0.42 & 49.9 & -1.3 & 8.6 & 2.7 \\
\hline RC10-175 & 34.6 & 159.2 & 15 & -- & 50.3 & -3.7 & 7.9 & 5.3 \\
\hline RC10-178 & 37.8 & 172.3 & 22 & -- & 57.9 & 0.7 & 13.0 & 7.3 \\
\hline RC10-179 & 39.6 & 173.7 & 10 & -- & 59.5 & 0.6 & 7.8 & 6.7 \\
\hline RC10-181 & 43.9 & 177.2 & 66 & 0.41 & 67.0 & 4.5 & 9.8 & 3.1 \\
\hline RC10-182 & 45.4 & 178.3 & 75 & 0.42 & 72.2 & 8.4 & 6.1 & 1.8 \\
\hline RC10-203 & 41.5 & 188.4 & 30 & 0.46 & 64.3 & 3.8 & 9.5 & 4.5 \\
\hline RC11-034 & -33.3 & 326.4 & 25 & -- & -58.5 & -5.8 & 4.3 & 2.2 \\
\hline RC11-104 & -40.9 & 57.6 & 5 & 0.59 & -61.7 & -1.7 & 3.0 & 4.2 \\
\hline RC11-105 & -38.8 & 58.8 & 36 & -- & -64.5 & -6.4 & 8.7 & 3.7 \\
\hline
\end{tabular}

Dashes indicate that the core shows no reversals and is presumed to be within the Brunhes normal and that the estimated age is set to zero. $p$ Lat, latitude of core site after correcting for absolute plate motion; $p$ Lon, longitude of core site after correcting for absolute plate motion; $n$, number of samples; Mean Age, average age of samples; Incl, maximum likelihood estimate of inclination; $\Delta$, inclination anomaly; $\sigma$, standard deviation of inclinations; $\alpha_{95}, 95 \%$ radius of confidence determined from $n$ and the maximum likelihood estimate of Fisher's precision parameter $K$. 
TABLE A2. (continued)

\begin{tabular}{|c|c|c|c|c|c|c|c|c|}
\hline Core & $\begin{array}{l}\text { pLat, } \\
\text { deg }\end{array}$ & $\begin{array}{l}\text { pLon, } \\
\text { deg }\end{array}$ & $n$ & $\begin{array}{c}\text { Mean } \\
\text { Age, Ma }\end{array}$ & $\begin{array}{l}\text { Incl, } \\
\text { deg }\end{array}$ & $\begin{array}{l}\Delta, \\
d e g\end{array}$ & $\begin{array}{c}\sigma \\
\text { deg }\end{array}$ & $\begin{array}{l}\alpha_{95} \\
\text { deg }\end{array}$ \\
\hline$\overline{\mathrm{RC11}-106}$ & -34.3 & 54.2 & 28 & -- & -57.2 & -3.4 & 6.0 & 2.9 \\
\hline RC11-166 & 43.8 & 171.2 & 20 & - & 63.2 & 0.8 & 4.8 & 2.8 \\
\hline RC11-170 & 44.2 & 197.1 & 29 & 0.52 & 75.3 & 12.5 & 3.5 & 1.7 \\
\hline RC11-171 & 46.4 & 200.7 & 32 & 0.45 & 71.0 & 6.5 & 3.7 & 1.7 \\
\hline RC11-193 & 39.7 & 220.3 & 8 & 0.55 & 55.0 & -4.0 & 2.2 & 2.2 \\
\hline RC11-209 & 3.5 & 220.2 & 43 & 0.33 & 20.1 & 13.1 & 12.0 & 4.7 \\
\hline RC11-213 & -6.3 & 219.6 & 13 & 0.49 & -8.0 & 4.5 & 3.9 & 2.8 \\
\hline RC11-227 & -6.1 & 245.8 & 42 & 0.42 & -20.2 & -8.2 & 11.1 & 4.3 \\
\hline RC12-065 & 4.4 & 215.5 & 10 & 0.61 & 7.6 & -1.2 & 8.9 & 7.6 \\
\hline RC12-066 & 2.4 & 212.2 & 37 & 0.45 & 9.6 & 4.7 & 6.5 & 2.7 \\
\hline RC12-083 & 3.5 & 195.3 & 26 & 0.45 & 2.3 & -4.6 & 7.1 & 3.5 \\
\hline RC12-084 & 2.1 & 195.2 & 31 & 0.45 & 2.0 & -2.2 & 6.0 & 2.7 \\
\hline RC12-224 & -51.4 & 226.9 & 19 & 0.48 & -72.3 & -4.1 & 7.0 & 4.2 \\
\hline RC12-299 & -34.1 & 358.9 & 26 & 0.42 & -56.6 & -3.0 & 5.9 & 2.9 \\
\hline RC12-320 & -6.6 & 47.8 & 27 & 0.19 & -9.0 & 4.0 & 9.5 & 4.7 \\
\hline RC12-327 & -1.8 & 57.8 & 57 & 0.37 & 2.1 & 5.6 & 7.4 & 2.4 \\
\hline RC12-331 & -2.7 & 69.8 & 50 & 0.44 & -9.6 & -4.3 & 6.0 & 2.1 \\
\hline RC12-333 & 0.7 & 76.1 & 20 & 0.20 & 1.8 & 0.4 & 6.9 & 3.9 \\
\hline RC12-334 & 2.2 & 77.2 & 18 & 0.36 & 7.9 & 3.4 & 13.4 & 8.3 \\
\hline RC12-339 & 9.0 & 90.0 & 15 & 0.20 & 21.2 & 3.6 & 11.2 & 7.7 \\
\hline RC12-340 & 12.7 & 90.0 & 10 & -- & 20.8 & -3.5 & 10.7 & 9.3 \\
\hline RC12-341 & 13.1 & 89.6 & 15 & -- & 22.7 & -2.2 & 8.5 & 5.8 \\
\hline RC13-210 & -9.2 & 349.3 & 27 & 0.60 & -20.4 & -2.5 & 5.4 & 2.6 \\
\hline RC13-212 & -9.5 & 352.1 & 14 & 0.65 & -21.4 & -2.9 & 4.6 & 3.2 \\
\hline RC13-213 & -10.5 & 357.6 & 7 & 0.48 & -27.2 & -6.9 & 2.8 & 3.0 \\
\hline RC13-238 & -30.9 & 356.8 & 16 & 0.41 & -44.4 & 5.8 & 9.4 & 6.2 \\
\hline RC13-241 & -35.6 & 353.3 & 28 & -- & -57.6 & -2.5 & 7.8 & 3.8 \\
\hline RC14-013 & -37.4 & 59.3 & 5 & 0.59 & -57.3 & -0.5 & 5.6 & 7.8 \\
\hline RC14-019 & -17.6 & 63.5 & 29 & 0.41 & -40.1 & -7.7 & 5.4 & 2.5 \\
\hline RC14-022 & -11.6 & 75.0 & 59 & 0.36 & -24.0 & -1.6 & 16.0 & 5.3 \\
\hline RC14-024 & -6.8 & 79.3 & 9 & 0.47 & -15.9 & -2.4 & 4.3 & 3.9 \\
\hline RC14-046 & -8.1 & 99.9 & 38 & 0.44 & -25.6 & -9.7 & 6.7 & 2.7 \\
\hline RC14-083 & 13.1 & 118.5 & 23 & -- & 25.9 & 1.0 & 10.1 & 5.4 \\
\hline RC14-103 & 44.0 & 152.9 & 131 & -- & 60.5 & -2.2 & 8.7 & 1.9 \\
\hline RC14-120 & 55.8 & 189.6 & 152 & .. & 51.0 & -20.2 & 12.1 & 2.5 \\
\hline RC15-020 & 4.9 & 228.4 & 27 & 0.45 & 7.3 & -2.4 & 6.6 & 3.2 \\
\hline RC15-021 & 1.4 & 227.4 & 71 & 0.41 & 0.0 & -2.8 & 6.7 & 2.0 \\
\hline RC16-055 & 10.4 & 314.7 & 19 & -. & 13.3 & -6.8 & 8.1 & 4.8 \\
\hline RC16-066 & -0.7 & 323.4 & 19 & -- & -8.1 & -6.6 & 12.3 & 7.4 \\
\hline RC16-076 & -13.3 & 343.9 & 15 & 0.44 & -23.0 & 2.2 & 7.5 & 5.1 \\
\hline RC16-077 & -12.7 & 346.5 & 7 & 0.35 & -29.3 & -5.1 & 5.9 & 6.3 \\
\hline RC16-166 & -0.5 & 316.9 & 18 & -- & -9.6 & -8.6 & 12.8 & 7.9 \\
\hline RC17-176 & 3.5 & 159.2 & 21 & 0.53 & 6.9 & -0.1 & 11.4 & 6.4 \\
\hline VM12-018 & -28.7 & 325.6 & 17 & 0.43 & -45.8 & 1.8 & 5.1 & 3.2 \\
\hline VM16-042 & -29.1 & 0.3 & 38 & 0.41 & -50.4 & -2.3 & 9.5 & 3.9 \\
\hline VM16-057 & -45.3 & 29.4 & 32 & 0.42 & -68.9 & -5.2 & 9.3 & 4.3 \\
\hline VM16-070 & -32.2 & 55.8 & 6 & 0.59 & -54.6 & -3.1 & 8.8 & 10.7 \\
\hline VM16-075 & -22.3 & 58.4 & 28 & 0.43 & -42.8 & -3.5 & 5.6 & 2.7 \\
\hline VM16-076 & -25.2 & 59.9 & 88 & 0.39 & -46.7 & -3.4 & 11.3 & 3.0 \\
\hline VM17-058 & -49.4 & 281.2 & 53 & -- & -63.1 & 3.7 & 7.3 & 2.5 \\
\hline VM18-166 & -35.0 & 332.9 & 30 & -- & -53.9 & 0.5 & 10.6 & 5.0 \\
\hline VM18-168 & -32.2 & 339.8 & 11 & -- & -56.0 & -4.5 & 12.8 & 10.6 \\
\hline VM18-177 & -31.5 & 0.1 & 12 & -- & -54.1 & -3.3 & 6.1 & 4.7 \\
\hline
\end{tabular}

Dashes indicate that the core shows no reversals and is presumed to be within the Brunhes normal and that the estimated age is set to zero. $p$ Lat, latitude of core site after correcting for absolute plate motion; $p$ Lon, longitude of core site after correcting for absolute plate motion; $n$, number of samples; Mean Age, average age of samples; Incl, maximum likelihood estimate of inclination; $\Delta l$, inclination anomaly; $\sigma$, standard deviation of inclinations; $\alpha_{95}, 95 \%$ radius of confidence determined from $n$ and the maximum likelihood estimate of Fisher's precision parameter $K$. 
TABLE A2. (continued)

\begin{tabular}{|c|c|c|c|c|c|c|c|c|}
\hline Core & $\begin{array}{l}\text { pLat, } \\
\text { deg }\end{array}$ & $\begin{array}{l}\text { pLon, } \\
\text { deg }\end{array}$ & $n$ & $\begin{array}{c}\text { Mean } \\
\text { Age, Ma }\end{array}$ & $\begin{array}{l}\text { Incl, } \\
\text { deg }\end{array}$ & $\begin{array}{c}\Delta, \\
\operatorname{deg}\end{array}$ & $\begin{array}{l}\sigma, \\
\operatorname{deg}\end{array}$ & $\begin{array}{l}\alpha_{95} \\
\text { deg }\end{array}$ \\
\hline VM19-153 & -9.1 & 102.0 & 69 & 0.39 & -23.3 & -5.5 & 6.0 & 1.8 \\
\hline VM19-154 & -11.4 & 101.4 & 29 & -- & -23.0 & -1.0 & 6.7 & 3.1 \\
\hline VM19-156 & -14.9 & 101.2 & 18 & 0.39 & -29.2 & -1.3 & 4.6 & 2.8 \\
\hline VM19-171 & -7.3 & 80.6 & 31 & 0.41 & -16.2 & -1.9 & 9.1 & 4.1 \\
\hline VM19-203 & -9.5 & 43.3 & 23 & -- & -20.2 & -1.7 & 6.1 & 3.2 \\
\hline VM19-300 & 6.9 & 340.5 & 11 & 0.50 & 9.4 & -4.2 & 7.8 & 6.3 \\
\hline VM19-301 & 8.3 & 337.2 & 42 & 0.43 & 16.7 & 0.4 & 16.8 & 6.7 \\
\hline VM19-302 & 10.2 & 334.6 & 42 & -- & 20.3 & 0.4 & 9.7 & 3.8 \\
\hline VM20-074 & 40.9 & 227.9 & 9 & 0.47 & 68.2 & 8.2 & 5.3 & 4.8 \\
\hline VM20-078 & 47.3 & 229.0 & 75 & -- & 67.4 & 2.2 & 7.9 & 2.3 \\
\hline VM20-080 & 46.3 & 225.3 & 6 & 0.58 & 67.3 & 2.8 & 1.8 & 2.2 \\
\hline VM20-085 & 44.7 & 216.7 & 13 & 0.52 & 59.5 & -3.7 & 8.6 & 6.3 \\
\hline VM20-087 & 41.6 & 210.5 & 8 & 0.57 & 65.8 & 5.2 & 7.0 & 6.9 \\
\hline VM20-088 & 40.0 & 208.7 & 10 & 0.51 & 53.6 & -5.6 & 2.4 & 2.0 \\
\hline VM20-091 & 37.1 & 202.7 & 10 & 0.49 & 59.4 & 2.9 & 5.6 & 4.7 \\
\hline VM20-092 & 36.1 & 200.7 & 10 & 0.47 & 58.3 & 2.7 & 8.9 & 7.7 \\
\hline VM20-094 & 34.4 & 197.1 & 11 & 0.47 & 55.1 & 1.3 & 5.4 & 4.3 \\
\hline VM20-097 & 31.8 & 191.7 & 12 & 0.53 & 56.3 & 5.2 & 5.7 & 4.4 \\
\hline VM20-098 & 30.9 & 189.9 & 12 & 0.53 & 47.3 & -2.9 & 2.9 & 2.2 \\
\hline VM20-102 & 30.9 & 182.7 & 8 & 0.57 & 50.2 & 0.1 & 3.1 & 3.0 \\
\hline VM20-105 & 38.7 & 182.2 & 9 & 0.55 & 65.4 & 7.3 & 5.8 & 5.3 \\
\hline VM20-107 & 43.2 & 181.5 & 40 & 0.45 & 55.9 & -6.1 & 6.4 & 2.6 \\
\hline VM20-108 & 45.2 & 181.3 & 36 & 0.58 & 60.5 & -3.1 & 7.6 & 3.2 \\
\hline VM20-109 & 47.1 & 180.8 & 12 & 0.51 & 56.9 & -8.2 & 6.1 & 4.7 \\
\hline VM20-119 & 47.7 & 169.2 & 34 & 0.46 & 68.8 & 3.2 & 13.3 & 6.2 \\
\hline VM20-167 & -21.2 & 72.3 & 35 & 0.42 & -49.2 & -11.4 & 12.7 & 5.5 \\
\hline VM20-184 & -25.9 & 53.7 & 58 & 0.40 & -51.7 & -7.6 & 8.2 & 2.7 \\
\hline VM20-234 & 5.3 & 327.0 & 16 & -- & 1.4 & -9.1 & 8.2 & 5.3 \\
\hline VM21-073 & 29.3 & 155.0 & 41 & 0.42 & 41.2 & -7.1 & 11.6 & 4.6 \\
\hline VM21-074 & 29.7 & 151.3 & 44 & 0.43 & 51.6 & 2.8 & 6.2 & 2.4 \\
\hline VM21-075 & 29.9 & 148.1 & 34 & 0.45 & 48.9 & -0.1 & 4.6 & 2.0 \\
\hline VM21-076 & 30.4 & 144.5 & 39 & -- & 51.2 & 1.6 & 9.8 & 4.0 \\
\hline VM21-087 & 27.9 & 146.6 & 53 & -- & 40.2 & -6.4 & 5.0 & 1.7 \\
\hline VM21-089 & 23.4 & 146.1 & 6 & 0.49 & 42.0 & 1.1 & 6.8 & 8.2 \\
\hline VM21-139 & 27.8 & 144.3 & 21 & -- & 46.1 & -0.4 & 6.2 & 3.5 \\
\hline VM21-140 & 28.4 & 147.4 & 13 & 0.49 & 47.7 & 0.5 & 3.7 & 2.7 \\
\hline VM21-141 & 30.6 & 154.5 & 16 & 0.47 & 52.0 & 2.2 & 7.5 & 4.9 \\
\hline VM21-142 & 31.4 & 156.9 & 24 & 0.48 & 57.3 & 6.6 & 5.7 & 3.0 \\
\hline VM21-144 & 32.5 & 160.4 & 259 & 0.39 & 45.9 & -6.0 & 5.5 & 0.8 \\
\hline VM21-145 & 33.9 & 165.3 & 41 & 0.44 & 60.3 & 7.0 & 9.4 & 3.8 \\
\hline VM21-146 & 37.7 & 163.0 & 16 & -- & 56.9 & -0.2 & 8.4 & 5.5 \\
\hline VM21-148 & 41.9 & 161.1 & 26 & 0.45 & 62.8 & 1.9 & 9.6 & 4.9 \\
\hline VM21-150 & 48.0 & 162.0 & 10 & -- & 67.3 & 1.5 & 4.3 & 3.7 \\
\hline VM21-171 & 49.9 & 195.1 & 156 & -- & 67.7 & 0.5 & 6.6 & 1.3 \\
\hline VM21-172 & 47.5 & 196.0 & 45 & 0.42 & 64.3 & -1.1 & 4.7 & 1.7 \\
\hline VM21-173 & 44.2 & 196.8 & 29 & 0.45 & 63.2 & 0.4 & 4.1 & 1.9 \\
\hline VM21-175 & 38.2 & 199.2 & 37 & 0.43 & 65.0 & 7.5 & 4.1 & 1.7 \\
\hline VM22-161 & -27.5 & 1.4 & 13 & 0.44 & -47.5 & -1.4 & 7.0 & 5.1 \\
\hline VM22-168 & -17.5 & 354.8 & 19 & 0.43 & -42.3 & -10.1 & 7.5 & 4.4 \\
\hline VM22-173 & -12.4 & 349.8 & 11 & 0.45 & -27.5 & -3.8 & 5.5 & 4.4 \\
\hline VM22-174 & -10.1 & 347.2 & 20 & -- & -16.7 & 2.9 & 10.4 & 6.0 \\
\hline VM22-175 & -8.8 & 345.7 & 35 & -- & -20.0 & -2.9 & 7.5 & 3.2 \\
\hline VM22-177 & -7.7 & 345.4 & 16 & -- & -18.7 & -3.5 & 9.5 & 6.2 \\
\hline VM22-182 & -0.5 & 342.7 & 17 & -- & -8.6 & -7.5 & 8.3 & 5.2 \\
\hline VM22-185 & 2.6 & 340.8 & 8 & -- & -4.8 & -9.9 & 7.3 & 7.2 \\
\hline VM22-188 & 4.7 & 339.1 & 19 & -- & 2.2 & -7.1 & 14.6 & 8.8 \\
\hline VM22-192 & 7.8 & 338.6 & 11 & 0.49 & 16.6 & 1.3 & 8.3 & 6.7 \\
\hline VM22-230 & 32.7 & 307.8 & 63 & 0.41 & 49.1 & -2.9 & 11.5 & 3.7 \\
\hline VM24-054 & 1.7 & 228.6 & 29 & 0.38 & -4.5 & -7.9 & 8.8 & 4.2 \\
\hline
\end{tabular}


TABLE A2. (continued)

\begin{tabular}{|c|c|c|c|c|c|c|c|c|}
\hline Core & $\begin{array}{l}\text { plat, } \\
\text { deg }\end{array}$ & $\begin{array}{l}\text { plon, } \\
\text { deg }\end{array}$ & $n$ & $\begin{array}{c}\text { Mean } \\
\text { Age, Ma }\end{array}$ & $\begin{array}{l}\text { Incl, } \\
\text { deg }\end{array}$ & $\begin{array}{l}\Delta, \\
\text { deg }\end{array}$ & $\begin{array}{l}\sigma, \\
\text { deg }\end{array}$ & $\begin{array}{l}\alpha_{95} \\
\text { deg }\end{array}$ \\
\hline VM24-058 & 2.1 & 218.7 & 44 & 0.43 & 0.1 & -4.1 & 9.0 & 3.4 \\
\hline VM24-059 & 2.4 & 214.9 & 26 & 0.46 & 5.4 & 0.6 & 8.8 & 4.4 \\
\hline VM24-060 & 2.6 & 211.4 & 30 & 0.45 & 6.5 & 1.3 & 11.6 & 5.4 \\
\hline VM24-062 & 2.8 & 206.8 & 15 & 0.51 & 2.4 & -3.3 & 7.7 & 5.2 \\
\hline VM24-104 & 4.6 & 171.4 & 10 & 0.52 & 11.0 & 1.8 & 4.5 & 3.9 \\
\hline VM24-107 & 1.9 & 165.7 & 31 & 0.41 & 2.6 & -1.2 & 8.8 & 4.0 \\
\hline VM24-240 & -31.7 & 331.9 & 21 & 0.45 & -57.7 & -6.7 & 4.3 & 2.4 \\
\hline VM25-044 & 11.5 & 314.9 & 17 & -- & 21.2 & -0.9 & 11.7 & 7.5 \\
\hline VM25-046 & 9.3 & 317.0 & 9 & -- & 9.9 & -8.3 & 7.8 & 7.1 \\
\hline VM25-065 & 2.3 & 314.1 & 14 & -- & 6.2 & 1.6 & 11.2 & 7.9 \\
\hline VM26-049 & 5.8 & 342.1 & 16 & -- & 7.4 & -4.1 & 13.3 & 8.8 \\
\hline VM26-051 & 6.0 & 341.7 & 36 & 0.44 & 12.6 & 0.7 & 5.6 & 2.4 \\
\hline VM26-083 & -29.3 & 322.9 & 21 & 0.42 & -45.2 & 3.1 & 7.0 & 3.9 \\
\hline VM26-098 & -2.2 & 328.9 & 17 & -- & -12.3 & -7.9 & 10.0 & 6.3 \\
\hline VM26-102 & -0.4 & 321.0 & 13 & 0.40 & -3.3 & -2.6 & 8.0 & 5.9 \\
\hline VM27-180 & 3.3 & 339.0 & 12 & -- & 7.5 & 0.9 & 9.9 & 7.6 \\
\hline VM27-239 & -7.9 & 358.4 & 20 & 0.51 & -20.8 & -5.4 & 9.6 & 5.5 \\
\hline VM28-179 & 4.5 & 220.8 & 82 & 0.43 & 8.3 & -0.6 & 11.5 & 3.2 \\
\hline VM28-185 & 2.7 & 213.8 & 29 & 0.53 & 3.2 & -2.2 & 10.0 & 4.8 \\
\hline VM28-202 & 1.4 & 184.4 & 6 & 0.67 & 7.7 & 4.9 & 6.6 & 7.9 \\
\hline VM28-205 & 3.4 & 178.9 & 9 & 0.53 & 2.2 & -4.5 & 5.0 & 4.5 \\
\hline VM28-222 & -11.5 & 174.9 & 44 & 0.43 & -36.2 & -14.0 & 4.6 & 1.7 \\
\hline VM28-237 & -1.1 & 163.6 & 47 & 0.42 & -2.9 & -0.7 & 4.9 & 1.8 \\
\hline VM28-238 & 0.9 & 160.8 & 94 & 0.38 & 0.7 & -1.0 & 9.4 & 2.4 \\
\hline VM28-239 & 3.0 & 159.6 & 71 & 0.52 & 1.7 & -4.4 & 7.3 & 2.1 \\
\hline VM28-355 & -10.6 & 100.4 & 22 & 0.26 & -29.9 & -9.4 & 9.0 & 4.9 \\
\hline VM29-030 & 2.9 & 76.2 & 67 & 0.39 & 7.9 & 2.0 & 13.5 & 4.2 \\
\hline VM29-034 & -5.6 & 74.3 & 11 & 0.49 & -7.0 & 4.0 & 4.4 & 3.6 \\
\hline VM29-039 & -7.9 & 77.2 & 10 & 0.53 & -19.4 & -3.8 & 12.3 & 10.7 \\
\hline VM29-040 & -10.7 & 77.9 & 13 & 0.45 & -15.9 & 4.7 & 7.2 & 5.2 \\
\hline VM29-043 & -12.6 & 74.9 & 20 & 0.54 & -32.6 & -8.6 & 9.1 & 5.2 \\
\hline VM30-036 & 5.4 & 332.7 & 57 & 0.55 & 10.7 & 0.1 & 9.2 & 3.0 \\
\hline VM30-045 & 6.3 & 340.1 & 17 & 0.53 & 8.1 & -4.3 & 7.2 & 4.5 \\
\hline VM33-014 & -43.8 & 118.4 & 11 & 0.49 & -63.3 & -0.8 & 5.0 & 4.0 \\
\hline VM33-054 & -11.3 & 84.5 & 12 & 0.46 & -20.4 & 1.3 & 8.0 & 6.2 \\
\hline VM33-055 & -4.9 & 81.6 & 8 & 0.43 & -10.3 & -0.5 & 6.2 & 6.1 \\
\hline VM34-053 & -6.4 & 89.5 & 24 & 0.43 & -19.5 & -6.9 & 7.5 & 3.9 \\
\hline
\end{tabular}

Dashes indicate that the core shows no reversals and is presumed to be within the Brunhes normal and that the estimated age is set to zero. $p$ Lat, latitude of core site after correcting for absolute plate motion; $p$ Lon, longitude of core site after correcting for absolute plate motion; $n$, number of samples; Mean Age, average age of samples; Incl, maximum likelihood estimate of inclination; $\Delta$, inclination anomaly; $\sigma$, standard deviation of inclinations; $\alpha_{95}, 95 \%$ radius of confidence determined from $n$ and the maximum likelihood estimate of Fisher's precision parameter $K$.

TABLE A3. Matuyama Age (Reverse Polarity) Data Set

\begin{tabular}{lrrrrrrrr}
\hline \multicolumn{1}{c}{ Core } & $\begin{array}{c}\text { pLat, } \\
\text { deg }\end{array}$ & $\begin{array}{c}\text { pLon, } \\
\text { deg }\end{array}$ & $n$ & $\begin{array}{c}\text { Mean } \\
\text { Age, Ma }\end{array}$ & $\begin{array}{c}\text { Incl, } \\
\text { deg }\end{array}$ & $\begin{array}{c}\Delta, \\
\text { deg }\end{array}$ & $\begin{array}{c}\sigma, \\
\text { deg }\end{array}$ & $\begin{array}{c}\alpha_{95} \\
\text { deg }\end{array}$ \\
\hline KN09-057 & 8.6 & 337.9 & 28 & 1.24 & 8.4 & -8.5 & 6.7 & 3.2 \\
MD81-369 & -10.8 & 79.3 & 58 & 1.63 & -16.5 & 4.5 & 5.1 & 1.7 \\
MD81-375 & -13.7 & 77.1 & 55 & 1.99 & -23.3 & 2.6 & 7.6 & 2.6 \\
RC08-052 & -42.1 & 100.7 & 56 & 1.57 & -63.9 & -2.9 & 11.8 & 4.1 \\
RC08-053 & -40.3 & 103.7 & 36 & 1.43 & -65.4 & -5.9 & 9.3 & 4.0 \\
RC08-081 & -48.7 & 202.5 & 10 & 1.62 & -62.9 & 3.4 & 8.2 & 7.1 \\
RC09-114 & -34.0 & 195.6 & 20 & 0.77 & -58.1 & -4.6 & 11.0 & 6.4 \\
RC109-119 & -23.8 & 188.8 & 15 & 0.92 & -35.4 & 6.0 & 10.3 & 7.1 \\
RC10-095 & 3.1 & 231.3 & 21 & 1.26 & 7.8 & 1.6 & 6.1 & 3.4 \\
RC10-159 & 30.6 & 163.8 & 56 & 1.54 & 47.7 & -2.1 & 7.1 & 2.4 \\
\hline
\end{tabular}

\footnotetext{
Conventions as in Table A2.
} 
TABLE A3. (continued)

\begin{tabular}{|c|c|c|c|c|c|c|c|c|}
\hline Core & $\begin{array}{l}\text { pLat, } \\
\text { deg }\end{array}$ & $\begin{array}{l}\text { pLon, } \\
\text { deg }\end{array}$ & $n$ & $\begin{array}{c}\text { Mean } \\
\text { Age, Ma }\end{array}$ & $\begin{array}{l}\text { Incl, } \\
\text { deg }\end{array}$ & $\begin{array}{l}\Delta, \\
\text { deg }\end{array}$ & $\begin{array}{l}\sigma, \\
\operatorname{deg}\end{array}$ & $\begin{array}{l}\alpha_{95} \\
\operatorname{deg}\end{array}$ \\
\hline RC10-160 & 32.0 & 161.0 & 57 & 1.24 & 49.7 & -1.6 & 6.8 & 2.2 \\
\hline RC10-161 & 32.4 & 159.6 & 48 & 1.61 & 51.8 & 0.0 & 5.9 & 2.1 \\
\hline RC10-164 & 31.1 & 159.0 & 46 & 1.56 & 50.6 & 0.3 & 6.7 & 2.5 \\
\hline RC10-167 & 33.1 & 151.2 & 44 & 0.77 & 57.0 & 4.5 & 6.6 & 2.5 \\
\hline RC10-171 & 32.0 & 154.3 & 55 & 1.28 & 55.5 & 4.2 & 8.6 & 2.9 \\
\hline RC10-181 & 43.7 & 177.7 & 32 & 0.93 & 64.0 & 1.7 & 9.1 & 4.1 \\
\hline RC10-182 & 45.3 & 178.6 & 25 & 0.81 & 67.6 & 4.0 & 7.2 & 3.7 \\
\hline RC10-203 & 41.1 & 189.2 & 33 & 1.38 & 55.6 & -4.6 & 6.7 & 3.0 \\
\hline RC11-104 & -40.9 & 57.5 & 12 & 1.64 & -55.7 & 4.3 & 2.5 & 1.9 \\
\hline RC11-170 & 44.0 & 197.5 & 42 & 1.15 & 71.0 & 8.4 & 7.4 & 2.9 \\
\hline RC11-171 & 45.9 & 201.4 & 58 & 1.50 & 74.7 & 10.5 & 5.0 & 1.7 \\
\hline RC11-193 & 39.3 & 221.0 & 35 & 1.58 & 55.4 & -3.2 & 10.7 & 4.6 \\
\hline RC11-209 & 3.2 & 220.9 & 26 & 1.21 & 12.1 & 5.7 & 9.5 & 4.8 \\
\hline RC11-213 & -6.7 & 220.5 & 23 & 1.48 & -14.3 & -1.1 & 10.3 & 5.5 \\
\hline RC11-227 & -6.2 & 246.3 & 28 & 0.99 & -16.3 & -4.0 & 9.1 & 4.3 \\
\hline RC12-063 & 5.3 & 218.7 & 21 & 1.60 & 1.6 & -9.0 & 7.6 & 4.2 \\
\hline RC12-065 & 4.0 & 216.5 & 35 & 1.73 & -0.3 & -8.2 & 8.3 & 3.5 \\
\hline RC12-066 & 2.0 & 213.0 & 64 & 1.50 & -3.5 & -7.5 & 7.6 & 2.4 \\
\hline RC12-083 & 2.9 & 196.3 & 58 & 1.64 & 2.3 & -3.6 & 8.6 & 2.8 \\
\hline RC12-084 & 1.6 & 196.2 & 67 & 1.69 & 0.3 & -2.8 & 7.4 & 2.2 \\
\hline RC12-224 & -51.7 & 227.9 & 46 & 1.27 & -65.9 & 2.5 & 9.1 & 3.4 \\
\hline RC12-299 & -34.1 & 358.9 & 9 & 0.84 & -56.4 & -2.8 & 7.0 & 6.4 \\
\hline RC12-327 & -1.9 & 57.8 & 51 & 1.58 & -6.8 & -2.9 & 11.6 & 4.1 \\
\hline RC12-331 & -2.8 & 69.6 & 14 & 0.86 & -17.2 & -11.6 & 7.9 & 5.6 \\
\hline RC13-210 & -9.2 & 349.3 & 19 & 0.79 & -18.5 & -0.6 & 5.2 & 3.1 \\
\hline RC13-212 & -9.5 & 352.0 & 10 & 0.79 & -19.8 & -1.2 & 4.4 & 3.8 \\
\hline RC13-213 & -10.5 & 357.5 & 20 & 1.40 & -24.5 & -4.1 & 6.0 & 3.5 \\
\hline RC13-231 & -27.2 & 5.2 & 33 & 1.62 & -50.3 & -4.6 & 11.5 & 5.1 \\
\hline RC13-238 & -31.0 & 356.7 & 19 & 1.21 & -53.9 & -3.7 & 8.7 & 5.2 \\
\hline RC13-277 & -44.7 & 15.6 & 31 & 1.25 & -67.6 & -4.4 & 5.7 & 2.6 \\
\hline RC14-013 & -37.4 & 59.2 & 44 & 1.59 & -51.1 & 5.7 & 9.4 & 3.6 \\
\hline RC14-014 & -35.9 & 59.9 & 188 & 1.19 & -58.0 & -2.6 & 7.9 & 1.4 \\
\hline RC14-019 & -17.7 & 63.5 & 24 & 1.23 & -51.4 & -18.8 & 6.2 & 3.2 \\
\hline RC14-022 & -12.1 & 74.6 & 92 & 1.49 & -29.2 & -6.0 & 12.6 & 3.3 \\
\hline RC14-023 & -10.0 & 76.1 & 34 & 1.80 & -27.8 & -8.5 & 6.9 & 3.0 \\
\hline RC14-024 & -7.4 & 79.0 & 37 & 1.59 & -14.1 & 0.4 & 8.9 & 3.7 \\
\hline RC14-046 & -8.3 & 99.8 & 13 & 0.83 & -21.8 & -5.5 & 6.8 & 4.9 \\
\hline RC15-020 & 4.5 & 229.3 & 32 & 1.54 & -2.7 & -11.6 & 13.8 & 6.2 \\
\hline RC15-021 & 1.0 & 228.3 & 71 & 1.49 & -7.3 & -9.4 & 7.9 & 2.3 \\
\hline RC16-077 & -12.7 & 346.5 & 8 & 1.05 & -15.7 & 8.5 & 10.5 & 10.4 \\
\hline RC17-083 & -32.0 & 54.0 & 21 & 1.38 & -54.0 & -2.7 & 4.6 & 2.6 \\
\hline RC17-176 & 3.3 & 159.8 & 72 & 1.20 & -6.5 & -13.0 & 11.5 & 3.4 \\
\hline VM12-018 & -28.6 & 326.0 & 46 & 1.63 & -51.2 & -3.7 & 6.3 & 2.3 \\
\hline VM16-042 & -29.1 & 0.2 & 20 & 0.86 & -52.7 & -4.6 & 8.6 & 5.0 \\
\hline VM16-057 & -45.4 & 29.3 & 64 & 1.37 & -64.6 & -0.9 & 7.4 & 2.3 \\
\hline VM16-070 & -32.3 & 55.7 & 53 & 1.73 & -53.7 & -2.0 & 6.9 & 2.4 \\
\hline VM16-075 & -22.4 & 58.3 & 44 & 1.55 & -44.3 & -4.8 & 9.1 & 3.5 \\
\hline VM16-076 & -25.2 & 59.9 & 5 & 0.75 & -62.4 & -19.1 & 8.3 & 11.5 \\
\hline VM19-153 & -9.4 & 101.9 & 33 & 0.93 & -21.0 & -2.7 & 9.0 & 4.0 \\
\hline VM19-171 & -8.0 & 80.2 & 27 & 1.94 & -20.6 & -4.9 & 5.4 & 2.7 \\
\hline VM19-301 & 8.3 & 337.2 & 6 & 0.76 & 16.1 & -0.2 & 8.7 & 10.5 \\
\hline V'M20-065 & 25.1 & 208.1 & 10 & 1.66 & 46.7 & 3.5 & 6.5 & 5.6 \\
\hline VM20-074 & 40.7 & 228.3 & 12 & 1.07 & 65.3 & 5.5 & 8.9 & 6.9 \\
\hline VM20-080 & 46.1 & 225.7 & 13 & 1.23 & 65.8 & 1.5 & 6.5 & 4.8 \\
\hline VM20-085 & 44.3 & 217.3 & 22 & 1.47 & 55.8 & -7.1 & 8.4 & 4.6 \\
\hline VM20-087 & 41.2 & 211.1 & 20 & 1.53 & 61.4 & 1.2 & 6.7 & 3.9 \\
\hline VM20-088 & 39.5 & 209.4 & 32 & 1.54 & 59.4 & 0.6 & 7.2 & 3.2 \\
\hline VM20-091 & 36.9 & 203.0 & 6 & 0.89 & 50.4 & -5.9 & 4.6 & 5.5 \\
\hline VM20-092 & 35.8 & 201.3 & 22 & 1.22 & 56.4 & 1.2 & 7.7 & 4.2 \\
\hline
\end{tabular}


TABLE A3. (continued)

\begin{tabular}{|c|c|c|c|c|c|c|c|c|}
\hline Core & $\begin{array}{l}\text { plat, } \\
\text { deg }\end{array}$ & $\begin{array}{l}\text { pLon, } \\
\text { deg }\end{array}$ & $n$ & $\begin{array}{c}\text { Mean } \\
\text { Age, Ma }\end{array}$ & $\begin{array}{l}\text { Incl, } \\
\text { deg }\end{array}$ & $\begin{array}{l}\Delta V, \\
\operatorname{deg}\end{array}$ & $\begin{array}{l}\sigma, \\
\operatorname{deg}\end{array}$ & $\begin{array}{l}\alpha_{95} \\
\text { deg }\end{array}$ \\
\hline VM20-094 & 34.1 & 197.6 & 14 & 1.09 & 47.2 & -6.4 & 5.5 & 3.8 \\
\hline VM20-097 & 31.4 & 192.5 & 24 & 1.50 & 46.4 & -4.3 & 10.0 & 5.2 \\
\hline VM20-098 & 30.5 & 190.7 & 23 & 1.50 & 59.4 & 9.7 & 8.7 & 4.7 \\
\hline VM20-102 & 30.5 & 183.5 & 41 & 1.54 & 50.8 & 1.2 & 6.1 & 2.4 \\
\hline VM20-105 & 38.2 & 183.2 & 48 & 1.68 & 58.5 & 0.9 & 6.5 & 2.4 \\
\hline VM20-107 & 42.8 & 182.2 & 76 & 1.24 & 65.3 & 3.6 & 7.2 & 2.1 \\
\hline VM20-108 & 45.0 & 181.7 & 83 & 1.09 & 71.7 & 8.3 & 10.2 & 2.9 \\
\hline VM20-109 & 46.6 & 181.8 & 83 & 1.60 & 62.7 & -2.0 & 6.9 & 1.9 \\
\hline VM20-119 & 47.3 & 170.3 & 35 & 1.52 & 62.7 & -2.5 & 11.7 & 5.1 \\
\hline VM20-167 & -21.5 & 72.1 & 12 & 1.00 & -43.9 & -5.7 & 7.1 & 5.4 \\
\hline VM20-184 & -25.9 & 53.6 & 62 & 1.16 & -52.7 & -8.5 & 8.6 & 2.7 \\
\hline VM21-073 & 29.0 & 155.7 & 35 & 1.09 & 45.4 & -2.6 & 9.0 & 3.9 \\
\hline VM21-074 & 29.4 & 151.9 & 36 & 1.10 & 52.0 & 3.5 & 5.8 & 2.4 \\
\hline VM21-075 & 29.7 & 148.7 & 24 & 1.03 & 53.8 & 5.0 & 8.5 & 4.5 \\
\hline VM21-089 & 23.2 & 146.7 & 11 & 1.12 & 38.5 & -2.1 & 8.6 & 7.0 \\
\hline VM21-140 & 28.2 & 147.9 & 17 & 1.00 & 39.3 & -7.7 & 7.7 & 4.8 \\
\hline VM21-141 & 30.4 & 155.2 & 14 & 1.11 & 48.2 & -1.3 & 5.8 & 4.1 \\
\hline VM21-142 & 31.1 & 157.6 & 23 & 1.18 & 54.7 & 4.3 & 5.5 & 2.9 \\
\hline VM21-144 & 32.3 & 160.8 & 89 & 0.82 & 40.9 & -10.8 & 6.0 & 1.6 \\
\hline VM21-145 & 33.5 & 166.1 & 30 & 1.28 & 52.4 & -0.5 & 8.3. & 3.9 \\
\hline VM21-148 & 41.5 & 162.1 & 28 & 1.49 & 55.1 & -5.4 & 5.1 & 2.4 \\
\hline VM21-172 & 47.2 & 196.5 & 41 & 1.07 & 59.9 & -5.2 & 7.7 & 3.0 \\
\hline VM21-173 & 43.6 & 197.8 & 65 & 1.74 & 54.6 & -7.7 & 7.6 & 2.4 \\
\hline VM21-175 & 37.9 & 199.8 & 28 & 1.10 & 62.4 & 5.1 & 4.9 & 2.3 \\
\hline VM22-161 & -27.5 & 1.4 & 21 & 1.11 & -55.9 & -9.8 & 10.1 & 5.8 \\
\hline VM22-168 & -17.5 & 354.7 & 10 & 0.95 & -34.7 & -2.5 & 10.7 & 9.2 \\
\hline VM22-192 & 7.8 & 338.6 & 13 & 0.93 & 12.9 & -2.4 & 10.0 & 7.4 \\
\hline VM22-230 & 32.7 & 308.0 & 34 & 1.17 & 46.7 & -5.4 & 8.4 & 3.6 \\
\hline VM24-054 & 1.6 & 229.0 & 5 & 0.85 & 0.8 & -2.3 & 5.3 & 7.2 \\
\hline VM24-058 & 1.7 & 219.5 & 51 & 1.35 & -2.8 & -6.3 & 7.2 & 2.5 \\
\hline VM24-059 & 1.9 & 215.9 & 32 & 1.66 & -6.0 & -9.8 & 9.4 & 4.2 \\
\hline VM24-060 & 2.1 & 212.3 & 56 & 1.58 & -5.5 & -9.8 & 11.2 & 3.8 \\
\hline VM24-062 & 2.3 & 207.9 & 48 & 1.74 & -4.4 & -9.0 & 6.9 & 2.5 \\
\hline VM24-104 & 4.1 & 172.3 & 30 & 1.62 & 9.3 & 1.1 & 3.5 & 1.6 \\
\hline VM24-107 & 1.5 & 166.5 & 49 & 1.38 & 4.3 & 1.3 & 7.6 & 2.7 \\
\hline VM24-221 & -32.1 & 357.0 & 39 & 1.59 & -50.7 & 0.7 & 9.3 & 3.8 \\
\hline VM24-240 & -31.7 & 332.2 & 40 & 1.47 & -54.4 & -3.4 & 4.2 & 1.7 \\
\hline VM26-051 & 6.0 & 341.7 & 6 & 0.78 & 5.3 & -6.6 & 3.8 & 4.5 \\
\hline VM26-102 & -0.4 & 321.1 & 7 & 0.83 & 1.1 & 1.8 & 11.6 & 12.6 \\
\hline VM27-239 & -7.9 & 358.4 & 24 & 0.95 & -21.9 & -6.4 & 5.4 & 2.8 \\
\hline VM28-179 & 4.0 & 221.7 & 135 & 1.56 & 0.2 & -7.8 & 10.1 & 2.2 \\
\hline VM28-185 & 2.3 & 214.6 & 55 & 1.56 & 2.1 & -2.5 & 7.2 & 2.4 \\
\hline VM28-202 & 0.9 & 185.3 & 87 & 1.73 & -3.2 & -5.1 & 6.7 & 1.8 \\
\hline VM28-205 & 2.8 & 180.1 & 32 & 1.90 & -3.4 & -8.9 & 5.6 & 2.5 \\
\hline VM28-222 & -11.9 & 175.6 & 47 & 1.31 & -25.0 & -2.1 & 7.6 & 2.8 \\
\hline VM28-237 & -1.3 & 164.0 & 12 & 0.82 & -5.1 & -2.6 & 4.8 & 3.6 \\
\hline VM28-238 & 0.7 & 161.2 & 24 & 0.82 & -5.5 & -6.9 & 11.8 & 6.2 \\
\hline VM28-239 & 2.7 & 160.4 & 157 & 1.36 & 3.1 & -2.3 & 8.6 & 1.7 \\
\hline VM29-034 & -6.0 & 73.9 & 23 & 1.57 & -14.5 & -2.6 & 12.1 & 6.5 \\
\hline VM29-039 & -8.4 & 76.9 & 63 & 1.63 & -26.2 & -9.7 & 10.0 & 3.1 \\
\hline VM29-040 & -11.3 & 77.5 & 35 & 1.76 & -32.3 & -10.5 & 4.8 & 2.0 \\
\hline VM29-043 & -13.0 & 74.5 & 45 & 1.67 & -25.0 & -0.1 & 8.4 & 3.1 \\
\hline VM30-045 & 6.3 & 340.0 & 72 & 1.60 & 8.3 & -4.1 & 15.4 & 4.6 \\
\hline VM33-014 & -44.2 & 118.2 & 13 & 1.02 & -66.6 & -3.8 & 4.1 & 3.0 \\
\hline VM33-054 & -11.7 & 84.2 & 24 & 1.42 & -26.2 & -3.6 & 6.8 & 3.5 \\
\hline VM33-055 & -5.7 & 81.1 & 6 & 2.08 & -6.9 & 4.5 & 5.0 & 6.0 \\
\hline
\end{tabular}


ACKNOWLEDGMENTS. We thank Lloyd Burckle, Jean-Pierre Caulet, Jim Hays, and Dave Johnson for sharing biostratigraphic information on many of the cores studied. We also appreciate the efforts of Rich Jarrard, Steve Cande, and Rob Van der Voo for their constructive comments. Curatorial assistance was supported by Office of Naval Research grant N00014-87-K-0204 and U.S. National Science Foundation grant OCE88-00001. The original paleomagnetic measurements on many of the Lamont cores used in this study were carried out under a variety of U.S. National Science Foundation grants. The current research was supported by the U.S. National Science Foundation grants OCE87-16672 and EAR88-17773. LamontDoherty Geological Observatory contribution 4559.

H. Jay Melosh was the editor in charge of this paper. He thanks R. G. French for his assistance in evaluating the technical content and P. L. Olson for serving as a cross-disciplinary referee.

\section{REFERENCES}

Andrews, J. A., True polar wander: An analysis of Cenozoic and Mesozoic paleomagnetic poles, J. Geophys. Res., 90, 7737-7750, 1985.

Anson, G. L., and K. P. Kodama, Compaction-induced inclination shallowing of the post-depositional remanent magnetication in a synthetic sediment, Geophys. J. R. Astron. Soc., 88, 673-692, 1987.

Bloxham, J., and D. Gubbins, The secular variation of the Earth's magnetic field, Nature, 317, 777-781, 1985.

Burckle, L. H., and N. D. Opdyke, Late Neogene diatom correlations in the Circum-Pacific, in Proceedings of the 1st International Congress on Pacific Neogene Stratigraphy, pp. 255-284, Kaiyo Shuppan, Tokyo, 1977.

Castro, J., and L. Brown, Shallow paleomagnetic directions from historic lava flows, Hawaii, Geophys. Res. Lett., 14, 1203-1206, 1987.

Ceyala, M. A., and B. M. Clement, Inclination shallowing in deep-sea sediments from the North Atlantic, Geophys. Res. Lett., 15, 52-55, 1988.

Champion, D. E., Holocene geomagnetic secular variation in the western United States: Implications for the global geomagnetic field, U.S. Geol. Surv. Open File Rep., 80-824, 314, 1980.

Chapman, S., and J. Bartels, Geomagnetism, 1042 pp., Clarendon, Oxford, England, 1940.

Clement, B. M., and D. V. Kent, A detailed record of the lower Jaramillo polarity transition from a southem hemisphere deep-sea sediment core, J. Geophys. Res., 89, 1049-1058, 1984.

Coe, R. S., The effect of shape anisotropy on TRM direction, Geophys. J. R. Astron. Soc., 56, 369-383, 1979.

Coupland, D. H., and R. Van der Voo, Long-term nondipole components in the geomagnetic field during the last 130 m.y., J. Geophys. Res., 85, 3529-3548, 1980.

Courtillot, V., and J. Besse, Magnetic field reversals, polar wandering, and core-mantle coupling, Science, 237, 1140-1147, 1987.

Cox, A., Frequency of geomagnetic reversals and the symmetry of the nondipole field, Rev. Geophys., 13, 35-51, 1975.

Cox, A., and R. R. Doell, eview of paleomagnetism, Geol. Soc. Am. Bull., 71, 645-768, 1960.

Creer, K. M., D. T. Georgi, and W. Lowrie, On the representation of Quaternary and late Tertiary geomagnetic fields in terms of dipoles and quadrupoles, Geophys. J. R. Astron. Soc., 33, 323-345, 1973.
Diehl, J. F., K. M. McClannahan, and T. J. Bornhorst, Paleomagnetic results from the Mogollon-Datil volcanic field, southwestern New Mexico, and a refined mid-Tertiary reference pole for North America, J. Geophys. Res., 93, 4869-4879, 1988.

Evans, M. E., Test of the dipolar nature of the geomagnetic field throughout Phanerozoic time, Nature, 262, 676, 1976.

Fraser-Smith, A. C., Centered and eccentric geomagnetic dipoles and their poles, 1600-1985, Rev. Geophys., 25, 1-16, 1987.

Georgi, D. T., Spherical harmonic analysis of palaeomagnetic inclination data, Geophys. J. R. Astron. Soc., 39, 71-86, 1974.

Griffiths, D. H., R. F. King, A. I. Rees, and A. E. Wright, The remanent magnetism of some recent varved sediments, Proc. R. Soc. London, Ser. A, 256, 359-383, 1960.

Gubbins, D., Thermal core-mantle interactions and timeaveraged paleomagnetic field, J. Geophys. Res., 93, 3413-3420, 1988.

Harrison, C. G. A., The paleomagnetic record from deep-sea sediment cores, Earth Sci. Rev., 10, 1-36, 1974.

Harrison, C. G. A., and T. Lindt, Comparison between the hotspot and geomagnetic field reference frames, Nature, 300, 251-252, 1982.

Hays, J. D., T. Saito, N. D. Opdyke, and L. H. Burckle, Pliocene-Pleistocene sediments of the equatorial Pacific: Their paleomagnetic, biostratigraphic, and climate record, Geol. Soc. Am. Bull., 80, 1481-1514, 1969.

Hospers, J., Rock magnetism and polar wandering, Nature, 173, 1183, 1954.

Irving, E. Paleomagnetism and Its Applications to Geological and Geophysical Problems, 399 pp., John Wiley, New York, 1964.

James, R. W., and D. E. Winch, The eccentric dipole, Pure Appl. Geophys., 66, 77-86, 1967.

Johnson, D. A., D. A. Schneider, C. A. Nigrini, J.-P. Caulet, and D. V. Kent, Pliocene-Pleistocene radiolarian events and magnetostratigraphic calibrations for the tropical Indian Ocean, Mar. Micropaleontol, 14, 33-66, 1989.

Kent, D. V., Post-depositional remanent magnetisation in deep-sea sediment, Nature, 246, 32-34, 1973.

Kent, D. V., and N. D. Opdyke, Paleomagnetic field intensity variation recorded in a Brunhes epoch deep sea sediment core, Nature, 266, 156-159, 1977.

Kent, D. V., and D. A. Schneider, Examination of the Cenozoic non-dipole field: Evidence for a substantial quadrupole in the early Tertiary (abstract), Eos Trans. AGU, 70, 314, 1989.

King, R. F., The remanent magnetism of artificially deposited sediment, Mon. Not. R. Astron. Soc., Geophys. Suppl., 7, 115-134, 1955.

Kono, M., Uniqueness problems in the spherical harmonic analysis of geomagnetic field direction data, $J$. Geomagn. Geoelectr., 28, 11-29, 1976.

Latham, A., Current progress in studies of secular and paleosecular variation of the Earth's magnetic field, Eos Trans. AGU, 69, 546-557, 1988.

Lee, S., A study of the time-averaged paleomagnetic field for the last 195 million years, Ph.D. thesis, Australian Natl. Univ., Canberra, 1983.

Livermore, R. A., F. J. Vine, and A. G. Smith, Plate motions and the geomagnetic field, I, Quatemary and late Tertiary, Geophys. J. R. Astron. Soc., 73, 153-171, 1983.

Livermore, R. A., F. I. Vine, and A. G. Smith, Plate motions and the geomagnetic field, II, Jurassic to Tertiary, Geophys. J. R. Astron. Soc., 79, 939-961, 1984.

McElhinny, M. W., and R. T. Merrill, Geomagnetic secular variation over the past 5 m.y., Rev. Geophys., 13, 687-708, 1975.

McFadden, P. L., and A. B. Reid, Analysis of paleomagnetic inclination data, Geophys. J. R. Astron. Soc., 69, 307-319, 1982. 
McNish, A. G., and E. A. Johnson, Magnetization of unmetamorphosed varves and marine sediments, J. Geophys. Res., 43, 401-407, 1938.

Menke, W., Geophysical Data Analysis: Discrete Inverse Theory, 260 pp., Academic, San Diego, 1984.

Merrill, R. T., and M. W. McElhinny, Anomalies in the time-averaged paleomagnetic field and their implications for the lower mantle, Rev. Geophys., 15, 309-323, 1977.

Merrill, R. T., and M. W. McElhinny, The Earth's Magnetic Field: Its History, Origin and Planetary Perspective, 401 pp., Academic, San Diego, 1983.

Merrill, R. T., and P. L. McFadden, Secular variation and the origin of geomagnetic field reversals, J. Geophys. Res., 93, 11,589-11,597, 1988.

Merrill, R. T., M. W. McElhinny, and D. J. Stevensen, Evidence for long-term asymmetries in the Earth's magnetic field and possible implications for dynamo theories, Phys. Earth Planet. Inter., 20, 75-82, 1979.

Minster, J. B., and T. H. Jordan, Present-day plate motions, $J$. Geophys. Res., 83, 5331-5354, 1978.

Morgan, W. J., Hotspot tracks and the opening of the Atlantic and Indian oceans, in The Sea, vol. 7, edited by C. Emiliani, pp. 443-487, John Wiley, New York, 1981.

Nevanlinna, H., and L. J. Pesonen, Late Precambrian Keweenawan asymmetric polarities as analyzed by axial offset dipole geomagnetic models, J. Geophys. Res., 88, 645-658, 1983.

Ninkovich, D., L. H. Burckle, and N. D. Opdyke, Palaeogeographic and geologic setting for early man in Java, in The Ocean Floor, edited by R. A. Scrutton and M. Talwani, John Wiley, New York, 1982.

Opdyke, N. D., Paleomagnetism of deep-sea cores, Rev. Geophys., 10, 213-249, 1972.

Opdyke, N. D., and J. H. Foster, Paleomagnetism of cores from the North Pacific, Geol. Soc. Mem., I26, 83-119, 1970.

Opdyke, N. D., and B. P. Glass, The paleomagnetism of sediment cores from the Indian Ocean, Deep Sea Res., Part A, 16, 249-261, 1969.

Opdyke, N. D., and K. W. Henry, A test of the dipole hypothesis, Earth Planet. Sci. Lett., 6, 139-151, 1969.

Pesonen, L. J., and H. Nevanlinna, Two successive reversal transitions from Crete described by a two-dipole model with standing and time varying components, J. Geomagn. Geoelectr., 40, 77-94, 1988.

Roberts, P. H., and M. Stix, $\alpha$-effect dynamos by the BullardGellman formalism, Astron. Astrophys., 18, 453-466, 1972.

Rochette, P., Is the low order zonal harmonic model for geomagnetic reversals an artifact of recording processes? IAGA Bull., no. 53, Part B, 200, 1989.

Schneider, D. A., An estimate of the long-term non-dipole field from marine magnetic anomalies, Geophys. Res. Lett., 15, 1105-1108, 1988.

Schneider, D. A., and D. V. Kent, Influence of non-dipole field on determination of Plio-Pleistocene true polar wander, Geophys. Res. Lett., 13, 471-474, 1986.
Schneider, D. A., and D. V. Kent, Inclination anomalies from Indian Ocean sediments and the possibility of a standing nondipole field, J. Geophys. Res., 93, 11,621-11,630, $1988 a$.

Schneider, D. A., and D. V. Kent, The paleomagnetic field from equatorial deep-sea sediments: Axial symmetry and polarity asymmetry, Science, 242, 252-256, $1988 b$.

Schneider, D. A., and D. V. Kent, Paleomagnetism of leg 115 sediments, in Proceedings of the Ocean Drilling Project, vol 115B, U.S. Govemment Printing Office, Washington, D. C., in press, 1990.

Shackleton, N. J., and N. D. Opdyke, Oxygen isotope and paleomagnetic stratigraphy of equatorial Pacific core V28-238: Oxygen isotope temperatures and ice volumes on a $10^{5}$ year and $10^{6}$ year scale, J. Quat. Res., 3, 39-55, 1973.

Shackleton, N. J., and N. D. Opdyke, Oxygen isotope and palacomagnetic evidence for early northern hemisphere glaciation, Nature, 270, 216-219, 1977.

Tauxe, L., and D. V. Kent, Properties of a detrital remanence carried by haematite from study of modem river deposits and laboratory redeposition experiments, Geophys. J. R. Astron. Soc., 77, 543-561, 1984.

Valet, J.-P., and C. Laj, Paleomagnetic record of two successive Miocene geomagnetic reversals in western Crete, Earth Planet. Sci. Lett., 54, 53-63, 1981.

Wilson, R. L., Permanent aspects of the Earth's non-dipole magnetic field over upper Tertiary times, Geophys. $J$. $R$. Astron. Soc., 19, 417-437, 1970.

Wilson, R. L., Dipole offset-The time-average palaeomagnetic field over the past 25 million years, Geophys. J. R. Astron. Soc., 22, 491-504, 1971.

Wilson, R. L., Palaeomagnetic differences between normal and reversed field sources, and the problem of far-sided and right-handed pole positions, Geophys. J. R. Astron. Soc., 28, 295-304, 1972.

Wilson, R. L., and J. M. Ade-Hall, Paleomagnetic indications of a permanent aspect of the non-dipole field, in Paleogeophysics, edited by S. K. Runcom, pp. 307-312, Academic, San Diego, 1970.

Wilson, R. L., and M. W. McElhinny, Investigation of the large scale palaeomagnetic field over the past 25 million years; eastward shift of the Icelandic spreading ridge, Geophys. J. R. Astron. Soc., 39, 570-586, 1974.

Witte, W. K., and D. V. Kent, A middle Camian to early Norian ( $225 \mathrm{Ma})$ paleopole from sediments of the Newark Basin, Pennsylvania, Geol. Soc. Am. Bull., 101, 1118-1126, 1989.

D. V. Kent, Lamont-Doherty Geological Observatory and Department of Geological Sciences, Columbia University, Palisades, NY 10964.

D. A. Schneider, Centre des Faibles Radioactivités, Laboratoire Mixte CNRS-CEA, Avenue de la Terrasse, 91198 Gif-sur-Yvette Cedex, France. 